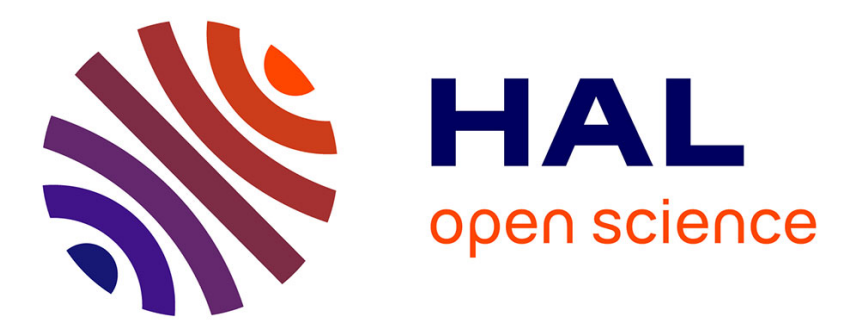

\title{
Exploring the behavior of suburban train users in the event of disruptions
}

Sonia Adele, Sabine Trefond Alexandre, Corinne Dionisio, Pierre Alain Hoyau

\section{To cite this version:}

Sonia Adele, Sabine Trefond Alexandre, Corinne Dionisio, Pierre Alain Hoyau. Exploring the behavior of suburban train users in the event of disruptions. Transportation Research Part F: Traffic Psychology and Behaviour, 2019, 65, pp 344-362. 10.1016/j.trf.2019.08.009 . hal-02267595v2

\section{HAL Id: hal-02267595 \\ https://hal.science/hal-02267595v2}

Submitted on 28 Jan 2021

HAL is a multi-disciplinary open access archive for the deposit and dissemination of scientific research documents, whether they are published or not. The documents may come from teaching and research institutions in France or abroad, or from public or private research centers.
L'archive ouverte pluridisciplinaire HAL, est destinée au dépôt et à la diffusion de documents scientifiques de niveau recherche, publiés ou non, émanant des établissements d'enseignement et de recherche français ou étrangers, des laboratoires publics ou privés. 


\section{Exploring the behavior of suburban train users in the event of disruptions}

Sonia Adelé ${ }^{a c *}$, Sabine Tréfond-Alexandre ${ }^{b}$, Corinne Dionisio ${ }^{a}$, Pierre-Alain Hoyau ${ }^{a}$

a Université Paris-Est / IFSTTAR / COSYS / GRETTIA 14-20 bd Newton - 77447 Marne-laVallée cedex 2 - France

b SNCF Research \& Innovation 40 avenue des Terroirs de France - 75611 Paris cedex 12 France

c IRT SystemX 8 avenue de la Vauve 91127 Palaiseau Cedex - France

* Corresponding author. Tel. : +33181668727. Email address: sonia.adele@ifsttar.fr

Declarations of interest: none.

Abstract

Little research has examined the behavior of public transport users in response to a service disruption that has just occurred. This article aims to identify the different ways in which suburban train passengers cope with service interruptions or delays and to identify the factors involved in their decision-making process. We conducted a study mixing two methods: a revealed-preference questionnaire that asked 185 participants about their choices during the last major disruption they encountered and a diary study in which participants described all disruptions they experienced during a two-week period. Eighty disruptions were reported in detail by 38 users. We analyze our results using multiple correspondence analysis and ascending hierarchical clustering to construct eight suburban train passenger behavioral profiles. Additionally, we compare different cases of disruption (in a multiple-case study). We identify three categories of factors affecting suburban train user behavior: individual-specific factors, journey-specific factors and information-specific factors. The findings show that user expertise, car availability, perception of service recovery time, opinions on passenger information services, available transport services, time constraints, and the moment and place at which communication about the disruption is received influence user behavior.

\section{Keywords}

User behavior, suburban train passenger choice, public transport, disruption, clustering, diary study.

\section{Introduction}

As of 2014, more than half of the world's population lives in cities (United Nations Department of Economic and Social Affairs, 2015). In 2050, this proportion is expected to rise to $66 \%$. Paris has not avoided this trend. SNCF Transilien, which is one of the main 
railway operators in the Greater Paris Region (Ile-de-France), has already had to cope with a $30 \%$ increase in passenger traffic on its lines in the last 10 years. This trend is set to accelerate, but the existing infrastructure and resources are already being stretched by the increasing number of passengers. In an overcrowded public transport network, a disruption may have a significant impact on operators and users. Gaining a better understanding of the behavior of passengers in multimodal transport systems, particularly in the event of a disruption, has thus become crucial. Such an understanding could allow policymakers to predict this behavior, propose personalized alternative routes, adjust the capacity on some lines, and provide alternatives such as temporary shuttle buses.

The research presented in this article sets out to describe and understand the short-term behavior of suburban train (Transilien) passengers in response to unplanned short service disruption. Its results identify behavioral rules that cover the different ways of coping with service interruptions or delays. These rules were input into a multi-agent system within software that simulated a multimodal public transport network (Tschirhart, Adelé, Bauguion, \& Tréfond, 2016). Compared to automobile user behavior, public transport user behavior in the event of a service disruption has received far less attention (Lin, Shalaby \& Miller, 2016). Too few studies pay attention to passenger behavior and preferences (Teng \& Liu, 2015), but adding passenger behavior (waiting, changing routes, using an alternative mode for traveling, cancelling trips) into transport modeling can improve predictions (Van der Hurk, Kroon, Li, Maroti, \& Vervest, 2010). Moreover, most studies on disruptions that consider behavior have been conducted based on assumptions instead of empirically measured behavior (Lin, Srikukenthiran, Miller \& Shalaby, 2018). Studies are also usually operator rather than passenger oriented (Golightly \& Dadashi, 2017; Pender, Currie, Delbosc \& Shiwakoti, 2013; Piner \& Condry, 2016).

In this study, a disruption is seen as an incident-related occurrence that causes more or less severe delays or service interruptions on one or two of three suburban train lines in the llede-France Region. These disruptions could be considered small in scale as they concern only a suburban line in a network (as opposed to large-scale long-term disruptions, as reviewed by Zhu \& Levinson, 2012). This research attempts to understand the immediate decision-making of suburban train users if their usual public transport route is no longer available in the short term or their travel time via their usual public transport route is increased because of an unexpected disruption. In other words, it focuses on situations in which a disruption has just occurred and has been communicated to users. It also aims to specify the individual and situational factors related to users' behavioral responses. To meet this objective, the research focuses on users' reactions to disruptions lasting from five minutes to less than one day (which occur more rarely) for technical (i.e., signals, power 
supply or track problems) or human reasons (rail suicide). These disruptions occur mostly on usual routes to or from work/school and are discovered at different stages of the trip (before starting the trip, at the departure station or en-route). Finally, passengers may have different levels of information about the cause, type or duration of the disruption. This paper comprises five sections. First, it presents a review of the current knowledge in the area of decision-making, the factors that influence choices and the measurement techniques used to study this topic. The second section outlines the procedure, the material and the sample used to conduct our study. The third section presents our empirical findings. Section four presents a discussion that situates our findings in relation to previous studies and describes the limits of our research. In the conclusion, we describe the principal contributions of this work and some perspectives.

\section{Literature review}

Since the initial work on individuals' absolute rationality, it has been accepted that there are limitations to decision-making. This theory of bounded rationality (Simon, 1955) postulates that decision-makers simplify their decisions, seeking satisfaction rather than optimization, and they make use of judgment heuristics, i.e., approximations based on experience. Individuals grasp the first alternative that is "good enough", according to their expectations. Individuals therefore seek a solution at the equilibrium between the time and effort required to find the solution and the solution's quality by applying the principle of cognitive economy (Chorus, Arentze, Molin, Timmermans, \& Van Wee, 2006a). Factors such as past experience, habit, or uncertainty influence this search for a sufficiently good solution. Habit inhibits active decision-making (Van der Horst, 2004) and the tendency to explore unfamiliar parts of a transportation network (Chorus, Molin, \& Van Wee, 2006b). A behavior becomes automatic when a decision reached by deliberation is considered to be satisfactory and the need to seek alternatives is lessened (Gärling, Fujii, \& Boe, 2001; Marsden \& Docherty, 2013; Schwanen, Banister, \& Anable, 2012; Verplanken, 2006). Like habit, uncertainty influences decision-making during a situation involving a disrupted trip because the exact characteristics of the alternatives (actual journey times, ridership) are in principle unknown (Chorus, Arentze, Timmermans, \& Van Wee, 2007). In view of this ignorance, individuals assess the cost/benefit ratio for the alternatives they consider on an uncertain basis (Bonsall, 2004).

The behavior of public transport users in response to a disruption has received little attention to date, and "the complexity of decision making of public transport user shows that empirical studies are needed to gain a better understanding" of this topic (Lin \& al, 2016, p. 2). Numerous studies have focused on the behavior of car drivers. Although some of these 
results may be relevant to our research, transport users and car drivers have different options and behavioral determinants in disruptive situations because two different groups (public transport and road users) with different characteristics are targeted (Nguyen-Phuoc, Currie, De Gruyter \& Young, 2018a). Public transport users are often captive users because the majority of them have no alternative mode of transport (Van Exel \& Rietvield, 2001). Moreover, the consequences of disruptions on road networks and public transport networks are different due to the latter's smaller size and limited number of alternative routes. Finally, the flow of information about disruptions is not the same on road and public transport networks. Information on road disruptions is usually more readily available to drivers (Lin \& al., 2016). Despite these differences, it is interesting to consider the numerous studies focusing on the impact of a disruption on drivers' behavior. In this area of research, a considerable body of work has focused on the role of sociodemographic characteristics such as age, gender (Zhang, Yun, \& Yang, 2012), or socio-occupational group on behavior (Emmerink, Nijkamp, Rietveld, \& Ommeren, 1996). Travelers' levels of habit and experience have also frequently been used to explain their behavior (Bonsall \& Palmer, 1999; Elia, Erev, \& Shiftan, 2008; Gärling \& Axhausen, 2003). More rarely, research has linked behavior with personality, particularly sensation seeking (Shiftan, Bekhor, \& Albert, 2011). According to the designer of the Sensation Seeking Scale, sensation seeking is "a personality trait defined by the seeking of varied, novel, complex, and intense sensations and experiences, and the willingness to take physical, social, legal and financial risks for the sake of such experience" (Zuckerman, 1994, p.27.) Shiftan, Bekhor and Albert (2011) have confirmed that a high level of sensation seeking tends to influence route choice, encouraging the selection of shorter but more variable routes. In addition, situational factors relate to the characteristics of a specific journey, such as trip purpose, distance, time of day (peak or off-peak periods), type of destination and the need to arrive on time (Peirce \& Lappin, 2004). With regard to information, existing research has focused on when it is received (Jou, 2001; Polak \& Jones, 1993), its content and form (Bonsall \& Palmer, 1999; Kitamura, Jovanis, Abdel-Aty, Vaughn, \& Reddy, 1999; Van Berkum \& Van der Mede, 1999), its quality, and how passengers react to it (Chorus, Molin, \& Van Wee, 2006b; Khattak, Yim, \& Stalker, 1999; Peirce \& Lappin, 2004). With regard to the moment at which information is received, Polak et Jones (1993) suggested that the earlier information is given, say, when individuals are still at home, the more choices are available to them (from cancelling the journey to changing their route, departure time or transport mode). This early step of the trip is called the "pre-trip" (Lin \& al., 2016).

The subject of public transport users' choices has been explored particularly in relation to public transport strikes (Nguyen-Phuoc \& al., 2018a, 2018b ; van Exel \& Rietveld, 2001, 
2009). Public transport strikes often result in complete service withdrawal. They affect not only passengers' usual routes but all public transit routes for one or more modes. Strikes can last a few days to a few weeks. Van Exel and Rietveld (2001) reviewed 13 studies of public transport strikes. The strikes lasted from one week to one month and affected all public transport modes in 8 cases and the entire network of one mode in 5 cases. In response to strikes, users must find a long-term solution. In our case, an unexpected disruption affects a passenger's usual route for a short time, but other public transport solutions are still available. Passengers choose from large set of possibilities within or outside of the public transport system. Another main difference exists between strikes and the kind of disruption we choose to study, which is that strikes are mostly announced (van Exel \& Rietveld, 2009). In France, strikes must be announced two days beforehand by workers, and a precise schedule is communicated to users the day before the strike begins. This allows time for users to analyze the situation and the alternatives. In contrast, in the case of an incident, a disruption has just occurred and has been communicated, and users immediately engage in decision-making process with a limited number of options while in a particular emotional state. Nevertheless, we find that the study of the 1999 train strike in the Netherlands is relevant for our study (Van Exel \& Rietveld, 2001). In this case, the first day of strike was unannounced because it was the result of violence against personnel. This strike lasted a few hours during morning peak time. There was no service in some regions, and there were severe delays in other regions. The information was poor or absent. One week after this strike, researchers surveyed 166 travelers and observed different behavioral adaptations for only approximately half of the commuters; these commuters cancelled their trip (10\%), left home later $(18 \%)$ or earlier $(10 \%)$, or changed their travel mode $(19 \%)$. The researchers highlighted the high level of inertia of commuters. The last difference between strikes and disruptions is that disruptions can occur at different steps of the trip, that is, before leaving home (pre-trip) or after leaving home (en-route), while passengers usually know about strikes before they leave home. Existing research findings identify interesting explanatory factors of strike effects on passenger behavior, highlighting three categories of factors (Nguyen-Phuoc \& al., 2018a): individual-specific factors, context-specific factors, and journey-specific factors. Individual-specific factors are car ownership, driver's license ownership, number of cars available in the household, number of adults in the household, and income. Context-specific factors are travel distance, travel time, travel cost, trip destination, weather, and flexibility. Journey-specific factors are accessibility to public transport stations and trip purposes. Concerning context-specific factors, Nguyen-Phuoc et al. (2018a) showed that a trip destination in a city center implies difficulties related to parking and congestion, which make the choice of traveling by car less suitable. Regarding the trip purpose (journey-specific factor), cancellations primarily occur for leisure trips, education-based trips, and work-related 
trips if the company allows employees to work from home. To the best of our knowledge, two studies have examined the impact of unexpected short-term disruptions on behavior, one in Calgary, Canada, and one in Toronto, Canada. The first performed a stated preference (SP) survey (Khattan \& Bai, 2018). The second used a combination of revealed preference (RP) and SP surveys (Lin \& al., 2018). In the first study, light rail transit passengers were asked about their behavior in disruption scenarios of different levels of severity and with different levels of information. Khattan and Bai (2018) proposed different explanatory factors of declared behavior, such as household vehicle ownership, the experience of the user, characteristics of other public transit paths (bus accessibility, location of the station, parking at the station), and the severity of the disruption. In that study, severity depended on the type of disruption (delay, interruption) and the service recovery time. In the second study, Lin et al. (2018) used questions about respondents' most recently encountered Toronto subway service disruption to enrich an SP experiment. The RP survey included questions about the origin and destination of the regular commuting trip (the characteristics of the trip were calculated by the Google Maps API), user characteristics (driver's license and vehicle access), disruption characteristics (date, time, location, type, duration) and behavior (mode chosen, additional travel time). Disruption scenarios were then generated for the SP experiment. RP and SP data revealed a mode split: $66 \%$ of the users chose to wait for the subway in the RP study, while only $11 \%$ did so in the SP study. A major limitation is that this study provided no information about the link between the delay (the severity of the disruption) and user behavior. The researchers chose not to ask respondents these questions for two reasons: it would have been difficult for them to remember this information, and, more importantly, they could have given post-incident information that was not available when they originally made their choices. Even if the cultural and infrastructural contexts and the methodology of these studies were different, they can serve as a basis for identifying which factors to explore.

Some studies consider all transport system users, including drivers and public transport passengers. They focus mainly on major natural disruptions. In a review, Zhu \& Levinson (2012) identify three behavioral effects—route change, departure time and mode shift-in the case of long-term and large-scale disruptions such as transit strikes, bridge closures, special events generating a higher transport demand, and earthquakes. In general, the most common adaptations concern route and travel time change, "while the magnitude of changes varies depending on the context" (Zhu \& Levinson, 2012, p.15). Zanni \& Ryley (2015) examine long-distance traveler attitudes and past responses to disruptions caused by extreme weather events (snow) or other natural causes (volcanic ash, hurricanes) through an internet-based survey in the United Kingdom. They attempt to understand individual, 
informational and contextual explanatory factors of this behavior, describing it as no change (chosen by the majority of respondents), time change, day change, cancellation, route change, destination change, departure point change, mode change, and companionship. Explanatory factors are the importance of the trip (linked with the purpose) and the severity of the disruption. The authors highlight the differences between the kind of trips they study and other types of trips, such as commuting, "with obviously different implications". Brazil, Caulfield \& O'Connor (2017) test pre-trip and on-trip hypothetical scenarios of weather disruption (heavy snow) to identify user behavior on different transport modes (car, rail and bus). For pre-trip scenarios, they find an impact of users' transport habits and gender. Lastly, Marsden, Anable, Shires and Docherty (2016) examine the behavioral response of travelers on different modes to major disruptions (snow and ice, flooding, bridge closure) based on multiple surveys administered during disruptions. Their method is novel because almost all the data in the literature are based on hypothetical scenarios, which have poor ecological validity, or post-event surveys, which are affected by recall and reconstruction biases. The data they obtain highlight interesting explanatory factors, including distance traveled, reason for the trip, time since the beginning of the disruption, type of disruption, experience with similar situations, level of multi-modality, employer attitude toward changing working patterns, and social networks. Observed behaviors for commute trips are mainly delayed starts and cancellations. Even if the disturbances studied in these works are very different from those that interest us in terms of space and time scales, the results obtained contain relevant elements to guide our work.

Psychological studies in transportation often use market segmentation to describe and explain passenger behavior. Such studies reduce the complexity and heterogeneity of the whole population by dividing it into relevant subgroups (Pronello \& Camusso, 2011; Anable, 2005; Hunecke, Haustein, Bohler \& Grischkat, 2010). Post hoc groups are specified on the basis of empirical results. Individuals are grouped with a cluster analysis according to their similarity in a specific set of variables. Haustein and Hunecke specify that "none of the approaches can claim absolute superiority. Instead, they show specific pros and cons, which suggests an application in different fields of the planning and design of mobility measures" (2013, p.201). In our study, we use post hoc behavioral segmentation based on empirical results, as our aim is to provide useful information for the creation of a realistic simulation tool. In addition to behavioral variables, socio-demographic, attitudinal, infrastructural and geographical variables are included in the analysis to overcome the oft-reported limitation of behavioral segmentation, that is, its lack of explanation of behavior (Hunecke \& al., 2010).

At a methodological level, existing studies are largely based on two widely used approaches: 
by presenting him or her with a series of hypothetical alternatives relating to a fictional journey presented in the form of a scenario (Nguyen-Phuoc \& al., 2018b). This is the approach most frequently applied in transportation studies (Emmerink et al., 1996; Polak \& Jones, 1993). While the presentation of fictional situations facilitates the administration of surveys and the analysis of results, the ecological validity of the findings is poor (Chorus, 2012). RP approaches analyze behaviors in real situations based on, for example, daily travel diaries, observations, or surveys that relate to past behaviors (Marsden \& al., 2016). Studies using RP provide data that are of good quality because they are more realistic (Bonsall \& Palmer, 1999), but RP can only be used to investigate phenomena that occurred during or shortly before the studied period. Some research uses interviews in addition to scenarios (Nuguyen-Phoc \& al., 2018a) or lived past situations (Grison, Gyselinck \& Burkhardt, 2016). Despite the limitations of this approach, we chose to focus on real situations of disruption by using a combination of methods: RP surveys related to past behaviors and diary studies related to repeated actual behaviors (Bolger \& Laurenceau, 2013). A diary was already performed to study behavioral adaptation in the case of strikes (Bonsall \& Dunkerley, 1997). The original aim of this study was to use concessionary travel permits for the elderly and people with disabilities in London. The diary survey period contained 6 days of an underground strike. Through a comparison, the researchers were able to highlight the impact of the strike on the travel behavior of this particular population; this behavior included a reduction in the number of trips and an increase of bus use. In our diary study, only disrupted trips were recorded. Every situation of an identified user facing a precisely characterized disruption was studied. This method could be considered as a multiple-case study, with one case being represented by one individual in different situations of disruption or different individuals in the same or similar situations of disruption. Case studies do not allow generalization of the results (Baxter \& Jack, 2008) but permit the proposal of in-depth ecologically valid results on a sample that is limited and not always representative. According to Yin (2003), a case study is useful to explore a situation in which behavior cannot be manipulated and to cover contextual conditions that are relevant to the phenomenon under study. We use a multiple-case study to explore situational and individual differences between cases. The evidence created from this type of study is considered robust and reliable (Baxter \& Jack, 2008).

The major aim of the study presented in this paper is to describe, analyze and understand the behavior suburban train passengers engage in to cope with disruptions that vary in their cause and severity. This study attempts to answer different questions: What would suburban train users do if their usual public transport route were no longer available in the short term because of a disruption? What would they do if their travel time via their usual public 
transport route were higher because of an incident? What are the main factors affecting people's choices in these contexts? To reach our goal, we decided to study a set of dimensions that have already been identified in the literature. The conceptual model consists of multidimensional factors affecting suburban trains users' choices. These factors can be classified into three categories: individual-specific factors (including personality and opinions), journey-specific factors, and information-specific factors. These dimensions will be described in detail in the "Material" section below.

\section{Method}

294

295

\subsection{Procedure}

A survey was conducted among suburban train passengers who travelled at least once a month on a selected part of the Transilien network (lines $U, C$ and $N$ ). In view of feasibility constraints, and to obtain realistic results, a two-phase survey was carried out. The first online questionnaire (Phase 1), which respondents completed only once, aimed to characterize respondents and their travel habits under normal and severely disrupted conditions. A section was added at the end of the questionnaire to recruit volunteers for the diary study. Respondents indicated whether they would agree to receive an email invitation to participate in the second phase of the study. The diary study (Phase 2) was then presented to the Phase 1 respondents who were willing to continue the survey. The diaries were to be filled in by the respondents within five minutes over a period of two weeks (outside school holidays) each time they felt they had been affected by an unplanned disruption on the studied lines, of whatever severity or cause. This diaries enabled us to establish a link between a specified disruption and the behavior of individual passengers. The two phases were administered online via the FluidSurveys website. On this website, we could modify the way the questionnaire and the diary were displayed to suit the type of device used by the respondents, i.e., a computer, smartphone or tablet. The survey provided no incentive to respondents beyond the possibility of receiving a summary of the results if they so wished. 
To contact users by email, we extracted individuals from a commercial database of adult holders of the public transportation card Navigo ${ }^{1}$, all of whom were willing to be contacted for such purposes. As the database does not contain any information on the mobility habits of users, we had to perform approximations to target individuals who used the three relevant train lines in applying a filter based on the municipality of residence (the only information we had). In total, 28,236 users living in 65 municipalities were contacted on March 5, 2015, through an email that contained a link to Questionnaire 1. Eighty percent of the users of the three lines studied live in these municipalities, according to the origin-destination survey of the operator ${ }^{2}$. A personalized reminder was sent out on March 13. At the end of the 15-day survey period, on March 19, 2,708 respondents were counted (a return rate of $9.59 \%$ ), of whom only 200 passed the screening process (line used and travel frequency) and completed the questionnaire. Our final sample comprised 185 respondents who adequately completed the questionnaire (a response rate of $0.65 \%$ ) on the basis of a quality check process (consistency of the answers and a lack of stereotyped answers).

\subsubsection{Diary study}

An email containing a link to the diary study was sent on March 20 to the respondents who were willing to take part in Phase 2. The diary was filled in by 38 participants during an 18day period from March 20 to April 6. Fifteen respondents completed the diary several times, and one participant completed it as many as seven times. Two reminders were sent out on March 25 and 30.

\subsection{Material}

The questionnaire and the diary were drafted based on the analysis of the current state of knowledge and 28 semi-directive interviews with regular and occasional users of the studied lines and French and foreign tourists (Martin, Adelé, \& Reutenauer, 2016).

\subsubsection{Questionnaire 1}

The first questionnaire took an average of 20 minutes to fill in and aimed to gain knowledge about the respondents and their perceptions. First, it enabled us to collect information on the suburban train passengers' past behavior in highly disruptive situations. The definition of a highly disrupted situation was deliberately left up to the individual respondent and gauged by a specific question. Respondents were also asked to estimate the frequency of disruptions

\footnotetext{
${ }^{1}$ The Navigo card offers unlimited travel by all public transport modes (bus, metro, suburban trains, tramway) in selected zones on a period from one week to one year.

${ }^{2} 12264$ respondents spatiotemporally representative of the users of the three lines studied with corrective weights applied on the basis of manual counts on a business day
} 
on their customary journeys and to describe the impact of these disruptions on their daily lives. They also reported the alternatives that were available to them in the event of a major disruption on their customary journey in both the outbound and return directions. The alternatives that were presented were as follows: changing routes while staying on public transport, changing modes (using a car, a motorized two-wheeler, or a bicycle or walking instead of using public transport), changing destinations, cancelling the trip (teleworking, taking a day off), and waiting. Respondents could give several responses. Then, a number of questions addressed the use and nature of other routes in the event of a disruption, the frequency with which the respondents changed route and the link between delays and such changes, with or without a time constraint. Part of the questionnaire was devoted to respondents' habits with regard to passenger information. They were thus asked whether they had subscribed to commuter service alerts, how frequently they consulted commuter information services, and what their opinion was on the information. They were also asked to state what information they usually received in the event of a disruption. Lastly, the questionnaire allowed us insight into the personality of the respondents by incorporating questions relating to the Sensation Seeking Scale developed by Zuckerman, Kolin, Price, \& Zoob (1964) and modified by Outwater, Castleberry, Shiftan, Ben-Akiva, Zhou, \& Kuppam (2003) as well as their individual characteristics such as age, gender, socio-occupational group, residential location and place of work. Passengers also answered questions about their opinions about their public transport journeys, the routines they employed during their trips and their level of knowledge about the network.

\subsubsection{Diary study}

To compensate for the recall nature of the first questionnaire, we used a diary to gather data in respondents' natural, spontaneous context. The aim was to establish a link between a real situation of disruption, of whatever level of severity, and an adopted behavior. During the study period, participants were able to fill in the diary each time they felt their trips had been affected by an unplanned disruption. The diary was designed to take less than five minutes to complete while still providing important information for the study, that is, the trip made, the disruption experienced (place, moment of communication, cause, type, duration), the information received, and the decision made by the respondent in response to this disruption.

To link the information given by the respondents to the situation of disruption, we also used data from the operator database. This database gives all information about each train that should have circulated on each day and line. This allowed us to assign different diary entries at the same event with more certainty. 
384

385

386

387

388

389

390

391

392

393

394

395

396

397

398

399

400

401

402

403

404

405

406

407

408

409

410

411

412

413

414

415

For Phase 1, the sample consisted of 185 respondents, $56 \%$ of whom were women. The sample was broken down into several age groups: $38 \%$ of the respondents were between 18 and 25 years old, $21 \%$ were between 26 and 39 years old, 35\% were between 40 and 59 years old, and $6 \%$ were over 60 years old, for an average age of 35 . The sample consisted of $37 \%$ executives, $26 \%$ intermediate professions, $33 \%$ students and $4 \%$ people who were not employed. Sixteen percent of the respondents lived in Paris, $14 \%$ lived in the inner suburbs, and $70 \%$ lived in the outer suburbs. Within the sample, line $\mathrm{N}$ was the most commonly travelled line, accounting for $40 \%$ of the respondents, while lines $\mathrm{C}$ and $\mathrm{U}$ accounted for $23 \%$ and $15 \%$, respectively. The remaining $22 \%$ of the sample principally used a combination of lines. On average, respondents' commute involved three separate modes, with 1.2 transfers between two modes of public transport or two lines. The trips lasted an average of 67 minutes, rising to 84 minutes in the event of disruptions. Of the respondents, $62 \%$ had been making this journey for more than a year.

To test the representativity of the sample, the sample was compared to figures collected in surveys conducted by Transilien ${ }^{3}$ (more than 10,000 passengers surveyed within our study zone) with regard to a number of criteria: frequency of use, journey time, number of modes used, gender, age, socio-occupational group, principal line used, station of origin, and experience. In our sample, users of lines $\mathrm{N}$ and $\mathrm{U}$ were overrepresented compared with users of line $\mathrm{C}$. Women were also overrepresented. In addition, students were overrepresented relative to economically active and inactive individuals. The "abnormal" distribution of socio-occupational groups can probably be explained by the dissemination mode we selected. Students and executives are perhaps the groups that are the most familiar with the internet and smartphones. Furthermore, the average age was slightly high, and the age distribution was atypical: the 26-39 age group was underrepresented, while the 18-25 age group and, above all, the 40-59 age group were overrepresented.

\subsubsection{Diary study}

Out of the 185 respondents in Phase 1, 38 reported between 1 and 7 disruptions. A total of 80 disruptions were reported during Phase 2, which ran from March 20 to April 6. The sample for Phase 2 matched that for Phase 1 fairly closely. Compared with the sample in the Transilien surveys, our sample was slightly more representative with regard to the age and socio-occupational group of the respondents. However, there were still too few 26-39-yearolds and too many executives.

\footnotetext{
${ }^{3}$ For reasons of confidentiality, the precise characteristics of the reference population have not been stated.
} 


\subsection{Data analysis design: questionnaire 1}

417 In our research, understanding the choices of public transport passengers during disruptions 418 using the questionnaire required three steps. The first step was the identification of variables 419 with an impact on behavior, mainly with $x^{2}$ analysis. The second step was to identify the 420 pattern of relationships of several categorical variables (behavioral variables) to be 421 interpreted by the use of multiple correspondence analysis. The third step was to define 422 homogeneous groups of users through cluster analysis.

\section{4. Results}

\subsection{Results from Questionnaire 1}

\subsubsection{Descriptive results: What did suburban train users tell us about their behavior} during disruptions?

427 The results presented in this section were obtained with SPSSC software.

- Decisions in the case of major disruptions on the outbound or return journey (Fig. 1)

429 Most of the respondents stated that they changed routes in the event of a major disruption 430 (defined as a delay of more than $30 \mathrm{~min}$ by $70 \%$ of the respondents). This applied to almost $43170 \%$ of the respondents on the outbound journey and slightly over $77 \%$ on the return journey.

432 Very few respondents waited in these situations (10.3\% on the outbound journey and $16.8 \%$ 433 on the return journey). In addition, on the outbound journey, $24 \%$ of the respondents either 434 decided not to travel (taking the day off or teleworking) or changed their destination. On the 435 outbound journey, $19.5 \%$ of the respondents transferred to another mode, compared with 436 only $13.5 \%$ on the return journey. The mode changes on the return journey often involved 437 calling on assistance from a third party (a family member, taxi or car-sharing). 
439

440

441

442

443

444

445

446

447

448

449

450

451

452

453

454

455

456

457

458

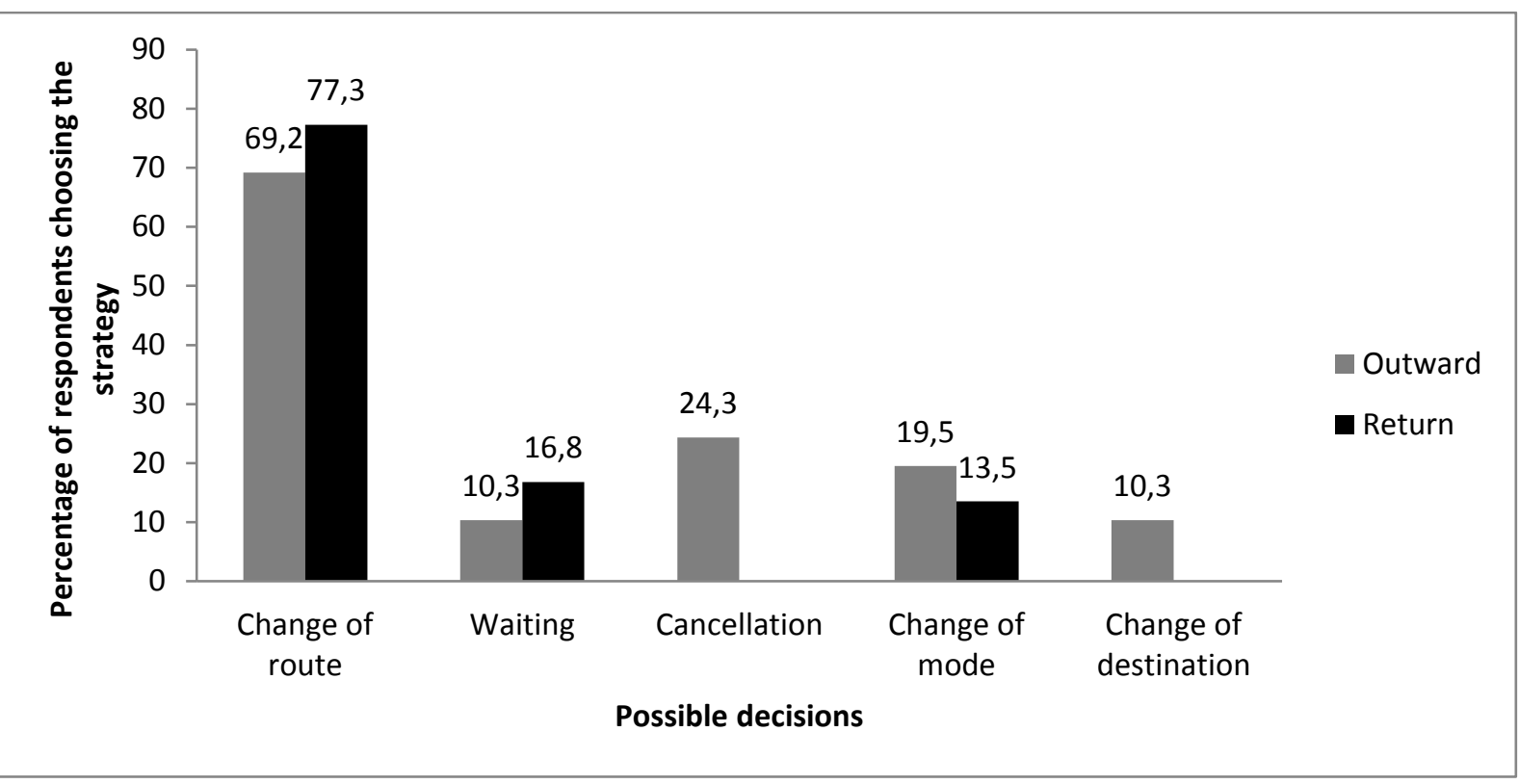

Fig. 1. Decisions reported by respondents in the event of major disruptions according to their direction of travel (multiple-choice question)

- Waiting time before changing routes with and without time constraints

The declared waiting times before changing routes were significantly different depending on whether the passengers had time constraints. The waiting time in the absence of time constraints was generally higher than that in the presence of time constraints $(Z=-3.68 ; p$ $<.001)$.

\section{- Route change}

The occurrence of a disruption affects the route chosen by suburban train passengers. Journey times increased to an average of 84 minutes during disruptions from an average of $67 \mathrm{~min}$ in normal situations $(Z=-7.21 ; p<.001)$. Moreover, in disruptive situations, the change in route altered the departure and arrival stations in $62 \%$ of cases. Depending on the distance, passengers went to the new station either on foot (a maximum distance of $1.8 \mathrm{~km}$ ) or by car (a maximum distance of $13 \mathrm{~km}$ ). The modes used were also different: private car (+ $86 \%)$, bus (+ $19 \%)$, metro (+ $31 \%)$, and tram (+ $567 \%)$. However, a disruption did not necessarily lead to more transfers during the journey. The usual route involved 1.2 transfers, while the alternative route involved 1.8 transfers on average.

\subsubsection{Bivariate analyses: How can we explain these behaviors?}


We have attempted to identify what individual-specific, journey-specific or informationspecific factors explain the different reactions with regard to the major disruptions. The statistical analyses were conducted using SPSS(0 software.

- Individual-specific factors

With regard to individuals, we have demonstrated the impact of household car ownership (access to a car) (Table 1). Those with access to a car use more the solution to change mode $\left(x^{2}(1)=22.27 ; p<.001\right)$ and less the solution to change route $\left(x^{2}(1)=7.84 ; p<.01\right)$ than others on outbound trips. Access to a car is associated with differences related to age and socio-occupational group. More specifically, the youngest respondents and students were less able to change modes on their outbound journey. These groups had significantly less access to a car than the others $\left(x^{2}(3)=15.24 ; p=.002\right)$.

Table 1. Access to a car and behavior on the outbound trip $(n=185)$

\begin{tabular}{rlrlr}
\hline & \multicolumn{2}{c}{ Change route } & \multicolumn{2}{c}{ Change mode } \\
& $\begin{array}{c}\text { Yes } \\
(n=128)\end{array}$ & $\begin{array}{c}\text { No } \\
(n=57)\end{array}$ & $\begin{array}{c}\text { Yes } \\
(n=36)\end{array}$ & $\begin{array}{c}\text { No } \\
(n=149)\end{array}$ \\
\hline Access to a car & & & & \\
Yes ( $n=82)$ & $58 \%$ & $42 \%$ & $34 \%$ & $66 \%$ \\
No $(n=103)$ & $78 \%$ & $22 \%$ & $7 \%$ & $93 \%$ \\
\hline
\end{tabular}

We have also shown that the expertise of suburban train passengers has an impact. In contrast to what we might have expected, the most experienced regular passengers (who had been using their daily route for more than one year) were less proactive with regard to seeking an alternative solution (Table 2). More particularly, a greater proportion of the most experienced passengers chose to wait on the return journey $\left(x^{2}(1)=4.73 ; p=.03\right)$ and wait longer than the others when they had no time constraints $\left(x^{2}(2)=6.48 ; p<.05\right)$ (Table 3 ). Similar results were obtained with regard to passengers' level of habit (Table 2). A strong habit leads to a greater propensity to wait on both the outbound journey $\left(x^{2}(2)=5.63 ; p=\right.$ $.06)$ and the return journey $\left(x^{2}(2)=7.76 ; p=.02\right)$.

\section{Table 2. Experience with the route, level of habit and waiting behavior}

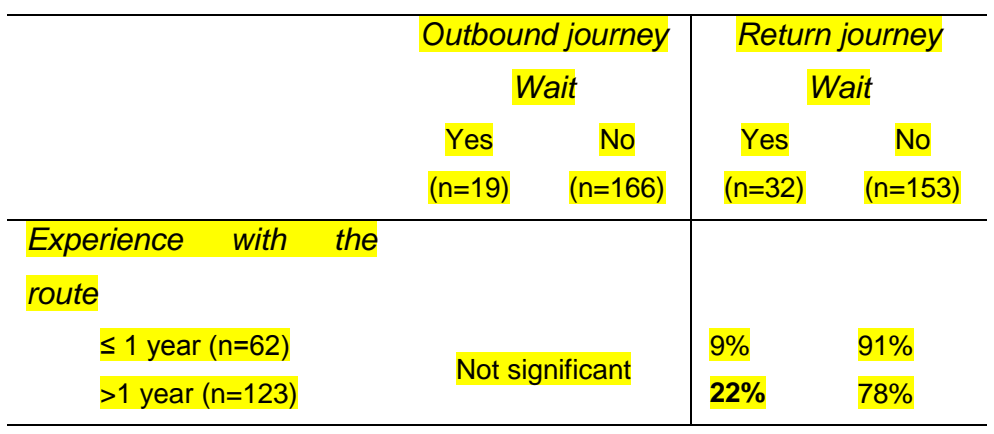




\begin{tabular}{cll|ll}
\hline Average level of habit & & & & \\
Low $(\mathrm{n}=64)$ & $3 \%$ & $97 \%$ & $6 \%$ & $94 \%$ \\
Medium $(\mathrm{n}=48)$ & $\mathbf{1 2 \%}$ & $88 \%$ & $\mathbf{2 3} \%$ & $77 \%$ \\
Strong $(\mathrm{n}=73)$ & $\mathbf{1 5 \%}$ & $85 \%$ & $\mathbf{2 2} \%$ & $78 \%$ \\
\hline
\end{tabular}

Table 3. Experience with the route and waiting time without time constraints

\begin{tabular}{llll}
\hline Waiting time without time constraints \\
\hline Less than 15 & From 15 to & More than 30 \\
$\min (n=54)$ & $30 \quad \min$ & $\min (n=66)$ \\
& $(n=65)$ & \\
& &
\end{tabular}

\begin{tabular}{|c|c|c|c|}
\hline Experience & the & & \\
\hline \multicolumn{4}{|l|}{ route } \\
\hline$\leq 1$ year $(n=62)$ & $43 \%$ & $30 \%$ & $27 \%$ \\
\hline$>1$ year $(n=123)$ & $22 \%$ & $39 \%$ & $40 \%$ \\
\hline
\end{tabular}

484

485 Finally, we have identified an impact of opinion on behavior (Table 4). A favorable opinion 486 toward traffic information leads to a greater tendency to change routes in the event of a 487 disruption on the return journey $\left(x^{2}(2)=8.05 ; p=.02\right)$.

Table 4. Opinion toward traffic information and route change on the return journey

\begin{tabular}{cll}
\hline & \multicolumn{2}{c}{ Change route } \\
& Yes $(\mathrm{n}=128)$ & No $(\mathrm{n}=57)$ \\
\hline Opinion toward traffic information & & \\
Negative $(\mathrm{n}=34)$ & $73 \%$ & $27 \%$ \\
Mixed $(\mathrm{n}=120)$ & $73 \%$ & $27 \%$ \\
Positive $(\mathrm{n}=31)$ & $97 \%$ & $3 \%$ \\
\hline
\end{tabular}

489

490

491

492

493

494

495

496

497

498

499

\section{- Journey-specific factors}

It seems to be clear that the opportunities for changing the route afforded by the transport network significantly alter the behavior of suburban train users when confronted by a major disruption. The position on the line is closely linked to the decision regarding whether to change routes on both the outbound journey $\left(x^{2}(2)=16.98 ; p<.001\right)$ and the return journey $\left(x^{2}(2)=6.99 ; p=.03\right)$. Comparing the respective numbers for these variables reveals that $a$ smaller proportion of individuals who started their journey at the end of the line reported changing their route (Table 5). Because the lle-de-France transport network is highly centralized, the passengers who live in remote outer suburbs have a low transport supply.

Table 5. Position of the departure station and route change behavior

Outbound journey Return journey




\begin{tabular}{cllcc} 
& \multicolumn{5}{c}{ Route change } \\
& $\begin{array}{c}\text { Yes } \\
(n=128)\end{array}$ & $\begin{array}{c}\text { No } \\
(n=57)\end{array}$ & $\begin{array}{c}\text { Yes } \\
(n=143)\end{array}$ & $\begin{array}{c}\text { No } \\
(n=42)\end{array}$ \\
\hline $\begin{array}{c}\text { Position on the line } \\
\text { Paris and inner suburbs }(\mathrm{n}=55)\end{array}$ & $75 \%$ & $25 \%$ & $85 \%$ & $15 \%$ \\
Outer suburbs ( $\mathrm{n}=68)$ & $82 \%$ & $18 \%$ & $81 \%$ & $19 \%$ \\
Remote outer suburbs $(\mathrm{n}=62)$ & $50 \%$ & $\mathbf{5 0 \%}$ & $66 \%$ & $\mathbf{3 4 \%}$ \\
\hline
\end{tabular}

- Information-specific factors

502 Our results reveal a link between changing modes on the outbound journey and subscribing 503 to the notifications sent out by the operator $\left(x^{2}(1)=4,01 ; p<.05\right)$. People who subscribed to 504 these services were more likely to change modes than persons who had not (Table 6). 505 Furthermore, suburban train passengers who decided to wait in a disruptive situation on the 506 return journey were unlikely to seek traffic information $\left(x^{2}(1)=5,71 ; p<.02\right)$ (Table 7$)$.

Table 6. Subscription to operator's notifications and mode change behavior on the outbound journey

\begin{tabular}{ccc}
\hline & \multicolumn{2}{c}{ Change mode } \\
& Yes & No \\
& $(n=36)$ & $(n=149)$ \\
\hline Subscription to operator's notifications & & \\
Yes $(n=90)$ & $26 \%$ & $74 \%$ \\
No $(n=95)$ & $14 \%$ & $86 \%$ \\
\hline
\end{tabular}

508

Table 7. Search for traffic information and waiting behavior on the return journey

\begin{tabular}{ccc}
\hline & \multicolumn{2}{c}{ Wait } \\
& Yes & No \\
& $(\mathrm{n}=32)$ & $(\mathrm{n}=153)$ \\
\hline Search for traffic information & & \\
Yes $(\mathrm{n}=66)$ & $5 \%$ & $95 \%$ \\
No $(\mathrm{n}=119)$ & $\mathbf{2 3 \%}$ & $77 \%$ \\
\hline
\end{tabular}

\subsubsection{A multivariate analysis: Can we identify suburban train passengers' behavioral} profiles?

513 Questionnaire 1 was mainly composed of nominal categorical questions with a finite number of response categories or modalities. For this kind of variable, the multiple correspondence 515 analysis (MCA) method is particularly suitable (Benzécri, 1992). Correspondence analysis is 516 a statistical technique for categorical data that is often used in social sciences. It permits 517 "more rapid interpretation and understanding of the data." (Greenacre, 2017, p.xi). MCA is a 518 factorial method that (similar to other methods in this family, such as the well-known principal 
component analysis) seeks optimal projections to summarize a dataset by exploiting the redundancy between the variables. The main difference between it and PCA relates to the nature of the processed data. MCA is performed by applying the correspondence analysis algorithm to a Burt table. It assigns scores to rows (representing the subjects) and columns (representing the response categories). MCA is largely descriptive (Le Roux \& Rouanet, 2010), and it is suitable for small samples because correspondence analysis is based on relative values. One question that arises when performing MCA concerns the number of dimensions to keep. It is possible, for instance, to examine a scree plot of eigenvalues to identify the elbow in descending sequences. The second question that arises is the interpretation of the axes. This interpretation is based on the modalities whose contribution to the axis exceeds their relative weight.

All respondents reported at least two behavioral choices for outbound and return trips, but some reported more choices in the event of a major disruption. It is therefore relevant to go beyond bivariate analysis and attempt to identify links between all behavioral variables. We performed multivariate analysis by applying MCA (Benzécri, 1992) using SPADC software. The analysis included nine behavioral variables (route change, mode change, destination change, waiting for the outbound and return trips, and cancellation of the outbound trip), which have two modalities: yes/no. The aim of this analysis is to highlight similar patterns of behavioral choices among users.

Table 8. Results of the MCA, histogram of the first eigenvalues

\begin{tabular}{|l|l|l|l|}
\hline Axis & Eigenvalues & Percentage & $\begin{array}{l}\text { Cumulative } \\
\text { percentage }\end{array}$ \\
\hline 1 & 0.2694 & 26.94 & 26.94 \\
\hline 2 & 0.1619 & 16.19 & 43.13 \\
\hline 3 & 0.1439 & 14.39 & 57.52 \\
\hline 4 & 0.1116 & 11.16 & 68.69 \\
\hline
\end{tabular}

The MCA results (Table 8 ) show that axis 1 largely explains the differences between the behavioral patterns in our sample. Although there is a considerable drop in the eigenvalues between the first two axes, the results prompt us to choose three axes rather than two because the "destination change on the return journey" and "cancellation on the outbound journey" variables are mainly present on the third axis. To describe the axes, we consider the modalities whose contribution exceeds their relative weight (Table 9). These axes are ways to understand the behavior of our sample in simplifying the information we have about it. In our case, we go from nine variables and eighteen modalities to 3 axes, each of them having two sides. 
Table 9. Results of the MCA, relative weight and contributions of active variables (values in bold are used for the

interpretation of the axis)

\begin{tabular}{|l|l|l|l|l|l|}
\hline & Modalities & $\begin{array}{l}\text { Relative } \\
\text { Weight }\end{array}$ & $\begin{array}{l}\text { Contribution } \\
\text { axis 1 }\end{array}$ & $\begin{array}{l}\text { Contribution } \\
\text { axis 2 }\end{array}$ & $\begin{array}{l}\text { Contribution } \\
\text { axis 3 }\end{array}$ \\
\hline \multirow{4}{*}{$\begin{array}{l}\text { Outbound } \\
\text { trip }\end{array}$} & Cancellation yes & 2.46 & 0.4 & 0.2 & $\mathbf{3 4 . 1}$ \\
& Cancellation no & 8.65 & 0.1 & 0.1 & $\mathbf{9 . 7}$ \\
\cline { 2 - 6 } & Route change yes & 7.69 & $\mathbf{7 . 6}$ & 0.5 & 1.8 \\
& Route change no & 3.42 & $\mathbf{1 7 . 0}$ & 1.0 & $\mathbf{4 . 1}$ \\
\cline { 2 - 6 } & Destination change yes & 0.36 & $\mathbf{1 . 2}$ & 0.1 & $\mathbf{1 2 . 8}$ \\
& Destination change no & 10.75 & 0.0 & 0.0 & 0.4 \\
\cline { 2 - 6 } & Mode change yes & 2.10 & 1.6 & $\mathbf{3 6 . 6}$ & 0.3 \\
& Mode change no & 9.01 & 0.4 & 8.5 & 0.1 \\
\cline { 2 - 6 } & Waiting yes & 1.14 & $\mathbf{1 6 . 7}$ & $\mathbf{8 . 3}$ & 2.5 \\
& Waiting no & 9.97 & 1.9 & 0.9 & 0.3 \\
\hline Return trip & Route change yes & 8.59 & 6.2 & 0.1 & 0.3 \\
& Route change no & 2.52 & $\mathbf{2 1 . 3}$ & 0.2 & 1.0 \\
\cline { 2 - 6 } & Destination change yes & 1.14 & 0.4 & 0.1 & $\mathbf{2 7 . 6}$ \\
\cline { 2 - 6 } & Destination change no & 9.97 & 0.0 & 0.0 & 3.2 \\
\cline { 2 - 6 } & Mode change yes & 0.66 & 0.8 & $\mathbf{3 6 . 0}$ & 0.0 \\
& Mode change no & 10.45 & 0.1 & 2.3 & 0.0 \\
\cline { 2 - 6 } & Waiting yes & 1.86 & $\mathbf{2 0 . 2}$ & $\mathbf{4 . 2}$ & 1.4 \\
& Waiting no & 9.25 & 4.1 & 0.8 & 0.3 \\
\hline
\end{tabular}

551

552 By considering the three axes, we can say that our sample can be described by three 553 dimensions: inaction or action (axis 1), car or no car available (axis 2), and possibility to adapt planned activities at the destination or not (axis 3).

555 It is interesting to use the MCA results for clustering. Ascending hierarchical clustering (AHC) 556 is a way to define homogeneous groups of passengers on the basis of the three strategies 557 resulting from the MCA. We do so using the Ward aggregation index. At each step of the 558 clustering, the two closest individuals are grouped, hence the representation by a 559 hierarchical tree (dendrogram). Cluster analysis does not offer a test to calculate the optimal 560 number of clusters (Hunecke \& al., 2010). It is possible to see the way the structure is formed 561 with the dendrogram and to select the optimal segmentation according to the hypotheses.

562 The interpretation of clusters relies on over- and underrepresented modalities by comparing 563 the relative frequency of the modality in the cluster and the frequency in the whole set (Le 564 Roux \& Rouanet, 2010). 
Then, the goal of the second phase of our work was to create a segmentation by hierarchical clustering using SPADC. The aim was to highlight the different groups of suburban train users according to similar behavioral patterns as well as individual-specific (car access, age, gender, socio-occupational group) or journey-specific (line used, position of the departure station on the line) factors.

Fig. 2. Part of the hierarchical clustering dendrogram of behavioral profiles

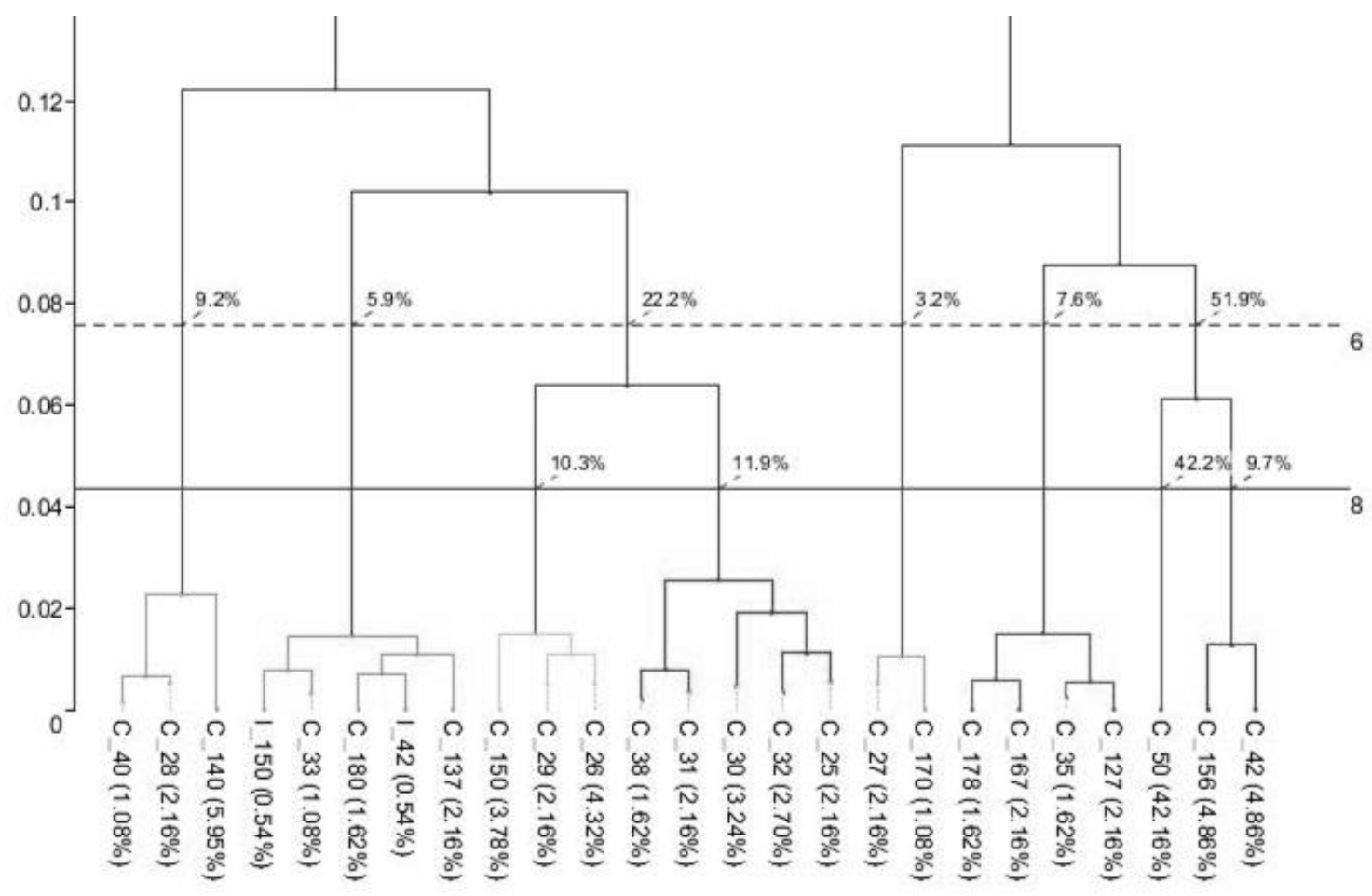

We estimate that the best partition of individuals consists of 8 clusters because there is a large jump from 0.02 to 0.06 in the dendrogram (Fig. 2). It would also be possible to choose a partition in 6 or 2 clusters, but we prioritize having the finest description of the groups of individuals. It is also notable that the smallest classes are still there in a 6-cluster partition. The size of the clusters is not too small.

The 8 clusters correspond to 8 behavioral profiles in the event of a major disruption, as defined in Table 3. By observing the modalities that are shared by the users in each cluster that is overrepresented compared with the other clusters, we can describe the typical behaviors and the characteristics that can be attributed to the cluster (Table 10). "Teleworkers" (11\%) were the only group in which no individual-specific or situation-specific factor was salient. The cancellation of outbound trips was common to all members of this group. Three groups shared a common way of coping with disruptions by changing routes; these groups were the "route changers" (42\%), the "flexible users" $(9 \%)$ and the "leisure users" (3\%). The "route changers", which comprised the major part of the sample, only 
changed routes, while the other groups also used other ways of coping. The "route changers"

587

588

589

590

591

592

593

594

595

596

597

598

599

600

601

602

603

604

605

606

607

608

609

610

611

612 did not live in the remote suburbs of Paris, where the transport system is less developed, and have a low access to a car. The "flexible users" are almost the only ones changing destinations on return trips. As these users are young and students, we think that they have less obligation to return home and have more opportunities to sleep at a friend's. The "leisure users" have the widest selection of solutions to cope with disruptions on outbound and return trips but are statistically represented by destination changes on outbound trips. This cluster includes a higher portion of pensioners than the others. As the cluster also includes workers and students, we think that it could also be called the "desk-sharer" cluster to indicate that some of its members have multiple workplaces or places of study. "Car owners" $(11 \%)$ and "passengers" (6\%) share the use of the car as a solution, the first as drivers of their own car (only on outbound trips) and the second as passengers. "Car owners" have access to a car and are more likely to be men and executives. On return trips, they mostly change their route. "Passengers" are the only group changing modes on return trips. They mostly live in the outer suburbs, which is why we call them "passengers" and not "car borrowers". The Autolib car-sharing service is only available in the inner suburbs and in Paris. The "constrained" group ( $9 \%)$ is the only group that mainly waits on outbound and return trips. They are mostly users of line $\mathrm{N}$ who live in the remote outer suburbs, where the transport system is less developed. Their range of solutions is wider for return trips. Individuals comprising the "passive on return trip cluster" almost all wait when an important disruption occurs on their return trip, while they do not wait on their outbound trip. We formulate the hypothesis that this group is composed of people with no familial or personal obligations in the evening. They prefer to use the waiting time to engage in other activities (such as having a drink or working longer).

Table 10. Behavioral clusters identified from the results of Questionnaire 1 (values in bold indicate that the corresponding modality is overrepresented, and values in grey indicate that the corresponding modality is underrepresented in the cluster)

\begin{tabular}{|c|c|c|c|c|c|c|c|c|}
\hline \multirow[t]{2}{*}{ Characteristics of the users } & \multicolumn{8}{|l|}{ Clusters (\%) } \\
\hline & $\begin{array}{l}\text { Teleworkers } \\
(n=20 ; 11 \%)\end{array}$ & $\begin{array}{l}\text { Route changers } \\
(n=78 ; 42 \%)\end{array}$ & $\begin{array}{c}\text { Flexible } \\
(n=16 ; 9 \%)\end{array}$ & $\begin{array}{l}\text { Leisure users } \\
\qquad(\mathrm{n}=6 ; 3 \%)\end{array}$ & $\begin{array}{l}\text { Passive on } \\
\text { return trip } \\
(n=16 ; 9 \%)\end{array}$ & $\begin{array}{l}\text { Car owners } \\
(\mathrm{n}=21 ; 11 \%)\end{array}$ & $\begin{array}{l}\text { Passengers } \\
(n=11 ; 6 \%)\end{array}$ & $\begin{array}{l}\text { Constrained } \\
(\mathrm{n}=17 ; 9 \%)\end{array}$ \\
\hline \multicolumn{9}{|l|}{ Gender } \\
\hline Male & 45.0 & 46.15 & 18.75 & 33.33 & 37.5 & 66.66 & 36.36 & 41.18 \\
\hline Female & 55.0 & 53.85 & 81.25 & 66.67 & 62.5 & 33.34 & 63.64 & 58.82 \\
\hline \multicolumn{9}{|l|}{ Age } \\
\hline $18-25$ & 30.0 & 37.18 & 68.75 & 50.0 & 50.0 & 14.29 & 45.46 & 17.65 \\
\hline $26-40$ & 25.0 & 20.51 & 18.75 & 16.66 & 12.5 & 23.81 & 18.18 & 29.41 \\
\hline $41-60$ & 30.0 & 35.90 & 6.25 & 16.67 & 37.5 & 57.14 & 18.18 & 47.06 \\
\hline $60+$ & 10.0 & 3.85 & 6.25 & 16.66 & 0 & 4.76 & 18.18 & 5.88 \\
\hline \multicolumn{9}{|l|}{$\begin{array}{l}\text { Behavior in case of major } \\
\text { disruption }\end{array}$} \\
\hline Route change - outbound & 50.0 & 100 & 68.8 & 83.3 & 50 & 38.1 & 54.5 & 11.8 \\
\hline Mode change - outbound & 0 & 0 & 6.3 & 16.7 & 31.3 & 100 & 72.7 & 0 \\
\hline Waiting - outbound & 0 & 0 & 6.3 & 0 & 0 & 0 & 9.1 & 100 \\
\hline Destination change - outbound & 0 & 0 & 0 & 100 & 0 & 0 & 0 & 0 \\
\hline Cancellation - outbound & 100 & 0 & 43.8 & 100 & 43.8 & 9.5 & 18.2 & 5.9 \\
\hline Route change - return & 90.0 & 100 & 68.8 & 100 & 12.5 & 85.7 & 45.5 & 29.4 \\
\hline
\end{tabular}




\begin{tabular}{|c|c|c|c|c|c|c|c|c|}
\hline Mode change - return & 20.0 & 2.6 & 12.5 & 0 & 6.3 & 19.0 & 100 & 5.9 \\
\hline Waiting - return & 0 & 0 & 0 & 0 & 93.8 & 14.3 & 0 & 76.5 \\
\hline Destination change - return & 0 & 0 & 100 & 33.3 & 0 & 0 & 9.1 & 0 \\
\hline \multicolumn{9}{|l|}{ Line usually used } \\
\hline Line $\mathrm{N}$ & 33.3 & 39.1 & 50.0 & 25.0 & 42.9 & 61.1 & 30.0 & 93.3 \\
\hline Line U & 13.3 & 21.7 & 14.3 & 0 & 21.4 & 16.7 & 20.0 & 0 \\
\hline Line C & 33.3 & 30.4 & 28.6 & 7.5 & 28.6 & 16.7 & 20.0 & 0 \\
\hline Combination of lines $\mathrm{N} 1 \mathrm{C}$ & 20.0 & 8.7 & 7.1 & 0 & 7.1 & 5.6 & 30.0 & 6.7 \\
\hline \multicolumn{9}{|l|}{ Employment position } \\
\hline Manager & 50.0 & 34.6 & 6.3 & 16.7 & 25.0 & 61.9 & 27.3 & 56.3 \\
\hline Technician & 5.0 & 7.7 & 6.3 & 0 & 6.3 & 9.5 & 0 & 6.3 \\
\hline Employee & 10.0 & 20.5 & 12.5 & 16.7 & 18.8 & 19 & 36.4 & 12.6 \\
\hline Student & 30.0 & 34.62 & 68.75 & 50.0 & 50.0 & 9.5 & 27.27 & 17.65 \\
\hline Unemployed & 0 & 1.3 & 0 & 0 & 0 & 0 & 9.1 & 6.3 \\
\hline Pensioner & 5 & 1.3 & 6.3 & 16.7 & 0 & 0 & 0 & 0 \\
\hline \multicolumn{9}{|l|}{ Access to a car } \\
\hline Yes, always & 40.0 & 17.9 & 18.8 & 16.7 & 31.3 & 57.1 & 36.4 & 29.4 \\
\hline Yes, often & 10.0 & 14.1 & 6.3 & 16.7 & 25.0 & 33.3 & 0 & 23.5 \\
\hline Yes, rarely & 15.0 & 24.4 & 18.8 & 16.7 & 12.5 & 4.8 & 18.2 & 17.6 \\
\hline No & 35.0 & 43.6 & 56.3 & 50.0 & 31.3 & 4.8 & 45.5 & 29.4 \\
\hline \multicolumn{9}{|l|}{$\begin{array}{l}\text { Position of the departure } \\
\text { station }\end{array}$} \\
\hline Remote outer suburbs & 30.0 & 23.08 & 50.0 & 0 & 50.0 & 38.10 & 27.27 & 64.71 \\
\hline Outer suburbs & 40.0 & 43.59 & 18.75 & 16.67 & 31.25 & 28.57 & 72.73 & 17.65 \\
\hline Inner suburbs & 5.0 & 15.38 & 18.75 & 50.0 & 18.75 & 14.28 & 0 & 5.88 \\
\hline Paris & 25.0 & 17.95 & 12.5 & 33.33 & 0 & 19.05 & 0 & 11.76 \\
\hline
\end{tabular}

\subsection{Results from the diary study}

615 The 38 passengers who took part in the second phase reported 80 disruptions (between one and seven each). We decided not to analyze disruptions in which the train stopped between stations, as this limited the passengers' available options to waiting. We therefore decided to analyze 67 reported events. Certain events were reported by 7 to 10 users; for example:

- a signaling malfunction that occurred on line $\mathrm{N}$ on March 26, 2015, from 4:30 to 11:40 AM with many train cancellations (10 users)

- a suicide that interrupted service for a few hours during the evening peak hours on line $\mathrm{C}$ on March 27, 2015 (7 users)

- track problems with an important slow of circulation and a reduction of the number of trains on line $C$ in the evening on March 26, 2015 (8 users)

- a switch failure that occurred on the three studied lines from the beginning of the evening peak hours until 9 PM on March 25, 2015, with important delays and train cancellations (8 users)

- a catenary break that caused delays on line $\mathrm{N}$ and interrupted trains' circulation on line $\mathrm{C}$ on April 3, 2015 (7 users)

Because of the great variety of studied disruptions (causes, location, duration), we choose to analyze suburban train users' reactions depending on the severity of the disruption. The severity is estimated by two distinct indicators: waiting time estimated by users who changed 633 strategy (In your opinion, how much time would you have waited if you had not made this choice?) and real waiting time reported by those who decided to wait (How long did you 
wait?). The result is 3 categories of severity: delays of less than $15 \mathrm{~min}$ (23 cases), delays from 15 to $30 \mathrm{~min}$ (20 cases) and delays of more than $30 \mathrm{~min}$ ( 23 cases).

First, the results of the diary study were processed by crossing the passengers' adopted behavior and the severity of the disruption. To facilitate analysis, all options that involved leaving the public transport network were recoded as a cancellation (destination change, cancellation of trip, exclusive use of a car, use of a two-wheeler, or walking to the destination).

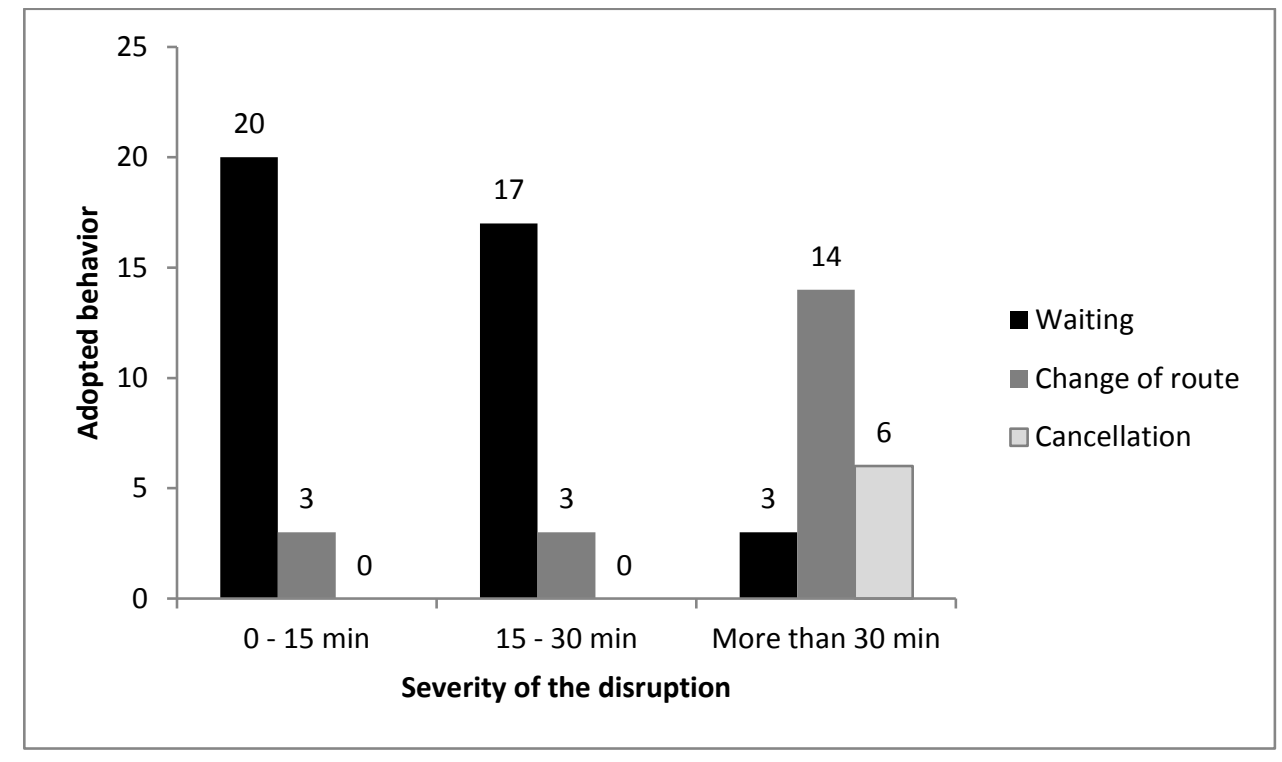

Fig. 3. Adopted behavior according to estimated or actual waiting time

The results (see Fig. 3) show that passengers prefer to wait in the case of disruptions that would make them wait less than $30 \mathrm{~min}$. However, for delays over $30 \mathrm{~min}$, cancellation appears as an option, and route change becomes the decision made by the majority.

However, not all respondents behaved in the same way. We then compared situations in which some individuals behaved differently from others at a given level of disruption severity. For example, we compared the three situations/passengers who chose to change routes in response to a minor disruption with the twenty who choose to wait (see Fig. 3). Conducting these comparisons enabled us to glimpse the possible impact of four factors on the behavior adopted by individuals: position on the line, time constraints, the step of the trip when the information was received (pre-trip or en route) and users' evaluation of the situation. More specifically, we observed that living at the end of a line could make it more difficult to change routes and encourage individuals to wait or cancel their journey. We have also seen that time constraints can have an impact. Individuals with time constraints behave in a more stereotyped manner and change their routes; other individuals seem to make more varied choices in accordance with their desires. We also observed that the information received had 
an impact. In the event of a minor disruption, receiving pertinent information when at home encourages individuals to wait before leaving for the station. In the event of a more serious disruption, receiving information at home encourages cancellation. Lastly, individuals' assessment of the severity of the situation may affect their decision. If they do not think they will have to wait a long time, they will use this solution. 11).

Table 11. Characteristics and behaviors of respondents with multiple diary entries (names are fictitious)

\begin{tabular}{|c|c|c|}
\hline Respondents & $\begin{array}{l}\text { Number } \\
\text { of diary } \\
\text { entries }\end{array}$ & Content of diary entries \\
\hline Julie, 49, employee, line $\mathrm{N}$ & s.m & $\begin{array}{l}2 \text { waiting: less than } 15 \text { min delay, disruption known at home } \\
4 \text { route changes: more than } 30 \text { min delay, disruption known at the train station }\end{array}$ \\
\hline Joshua, 21, student, lines $\mathrm{N}$ and $\mathrm{C}$ & 4 & $\begin{array}{l}3 \text { waiting: less than } 30 \text { min delay } \\
1 \text { mode change (for car): more than } 30 \text { min delay }\end{array}$ \\
\hline $\begin{array}{l}\text { Christopher, 39, manager, lines } \mathrm{N} \\
\text { and } \mathrm{C}\end{array}$ & 4 & $\begin{array}{l}1 \text { waiting: delay between } 15 \text { and } 30 \text { min } \\
1 \text { route change: delay between } 15 \text { and } 30 \text { min } \\
2 \text { mode changes (car): more than } 30 \text { min delay, high temporal constraints, disruption } \\
\text { known at home }\end{array}$ \\
\hline Paul, 45, technician, lines $\mathrm{N}$ and $\mathrm{C}$ & 5 & $\begin{array}{l}3 \text { waiting: less than } 30 \text { min delay } \\
1 \text { route change: more than } 30 \text { min delay, return trip } \\
1 \text { mode change (car): more than } 30 \text { min delay, outbound trip, high temporal constraints }\end{array}$ \\
\hline Thomas, 22, manager, line $\mathrm{N}$ & 4 & $\begin{array}{l}3 \text { waiting: outbound trip } \\
1 \text { route change: return trip }\end{array}$ \\
\hline Lisa, 49, employee, line C & 7 & $\begin{array}{l}3 \text { waiting: return trip } \\
3 \text { route changes: more than } 30 \text { min delay, return trip } \\
1 \text { teleworking: more than } 30 \text { min delay, outbound trip }\end{array}$ \\
\hline $\begin{array}{l}\text { Melissa, } 39, \quad \text { intermediate } \\
\text { profession, lines } \mathrm{N} \text { and } \mathrm{C}\end{array}$ & 2 & $\begin{array}{l}1 \text { waiting: less than } 15 \text { min delay } \\
1 \text { route change: more than } 15 \text { min delay }\end{array}$ \\
\hline Jessica, 19, student, line C & 2 & $\begin{array}{l}1 \text { waiting: less than } 30 \text { min delay } \\
1 \text { route change: more than } 30 \text { min delay }\end{array}$ \\
\hline
\end{tabular}

668

We observe that the severity of the disruption has a major impact on the chosen behavior for seven cases. The severity of disruptions that result in waiting appears to differ from the severity of disruptions that lead to changes, switching to a car or cancelling the trip. However, the severity of the disruption is not the only determinant; the threshold above which waiting is no longer the preferred option varies between 20 and 40 min depending on the individuals and the situations described. Different situational variables seem to influence the choices of users at a less distinct level; these variables include time constraints, the direction of the trip (outbound or return), and the moment at which the disruption is communicated. These factors are observed for only two or three users. Weak time constraints can encourage waiting, while strong ones can lead individuals to favor other strategies, especially car use. It is likely that the direction of the trip is linked to the behavior of three respondents. When at home, suburban train users are more likely to cancel their trip or to use their car. Lastly, this comparison suggests an influence of the time at which users receive information on their behavior (for two users), as we observed in the previous section. Receiving information when en-route (even if at the departure station) encourages individuals to change 
routes, while if they receive it pre-trip, it encourages them to wait, use a car, or cancel their trip.

These results should be considered invitations for further empirical research. Indeed, the use of situations of real disruptions encountered by individuals with different characteristics and in different situations does not allow comparisons with large samples. If only two users describe an effect of time constraints, this does not necessarily mean that there is no effect for the others; rather, it means that the time constraints were at the same level for the others in the cases they reported.

\section{Discussion}

Despite the importance of this topic, little research has focused on the behavior of suburban train passengers when faced with an unexpected disruption (Lin \& al., 2016). Most of the studies in this area focus on the complete withdrawal of public transport; planned, long-term disruptions; transport users in general; or motorists' behavior. Our study has highlighted possible determinants of the short-term behaviors of suburban train users in unplanned short-term disruptive situations caused by technical or human factors. This type of disruption is the one most commonly encountered by suburban train users in the lle-de-France Region. With regard to the method, we used a two-step RP survey: a questionnaire about the last major disruption encountered and a diary study about all disruptions encountered by a respondent during a two-week period. While diary studies have been used to understand mobility behavior, they have not been used to understand behavioral adaptation to disruptions. Only the diary study by Bonsall and Dunkerley (1997) examined the impact of information about a strike, even though the study had another initial aim. Using a diary study, we performed an in-depth analysis of the link between a clearly described disruption and a particular user in a particular situation. We also identified the types of strategies adopted as a reaction to major or less severe disruptions in order to create a realistic passenger flow model. After a short discussion regarding behavioral choices in case of disruption, the first part of the next section discusses factors influencing suburban train passengers' behavior when faced with a disruption. The second part reflects on the identified behavioral profiles. In the final part, limitations of the study are discussed.

\subsection{Behavioral choice in case of severe disruption}

In our study, suburban train users considered route changes as the first choice when faced with a severe disruption (between 70 and $77 \%$ users made this choice, depending on the direction of the trip). Lin \& al. (2018) found a similar result, but a smaller portion of their sample (39\%) made this choice. Van Exel and Rietvield (2001) obtained a very different 
result, with the majority of commuters leaving home as usual and using the disrupted mode. In the case of a pre-announced strike, the main behavior was mode change. For example, in the context of train strikes, van Exel \& Rietvield (2009) found a $24 \%$ mode change to cars. In our situation of a disruption on passengers' usual line, the rate of change to a car was between 13 and $20 \%$, depending on the direction of the trip. On complete public transport withdrawal, Nguyen-Phuoc et al. (2018b) found a 51.7\% mode change to a car as a driver. In the case of weather or natural events, cancellation, route change and travel time changes were mainly observed (Zhu \& Levinson, 2012; Marsden \& al., 2016). It seems that depending on the type, severity, magnitude, and duration of a disruption, the behavior of transport users changes. It is also very likely that the location of the place where the disruption occurs impacts the available solutions and the choices that are made (Marsden \& al., 2016).

Our study also shows what could be considered an acceptable route alternative by suburban train users by focusing on real choices: an average increase of $25 \%$ of the trip duration and the use of different modes, mostly a change in the origin or destination stations, implying the use of walk or car to reach the new station or walking to reach the destination. However, the number of transfers between two modes of public transport or two lines of the same public transport mode seems to remain relatively close. This could indicate that users prefer not to complicate their trips. Such precise information is scarcely available in the literature. Only the diary study by Bonsall and Dunkerley (1997) shows an increase of bus use during subway strikes.

\section{7}

\subsection{Factors influencing behavior}

738 Even if the severity of a disruption seems to be the greatest contributing factor to the 739 selection of alternatives, the findings show that passenger shifts are influenced not by one 740 factor alone but by a combination of linked factors. Fig. 4 proposes a summary of the 741 statistically significant factors influencing suburban trains users' behavior in the event of a 742 disruption (from section 4.1.2). 


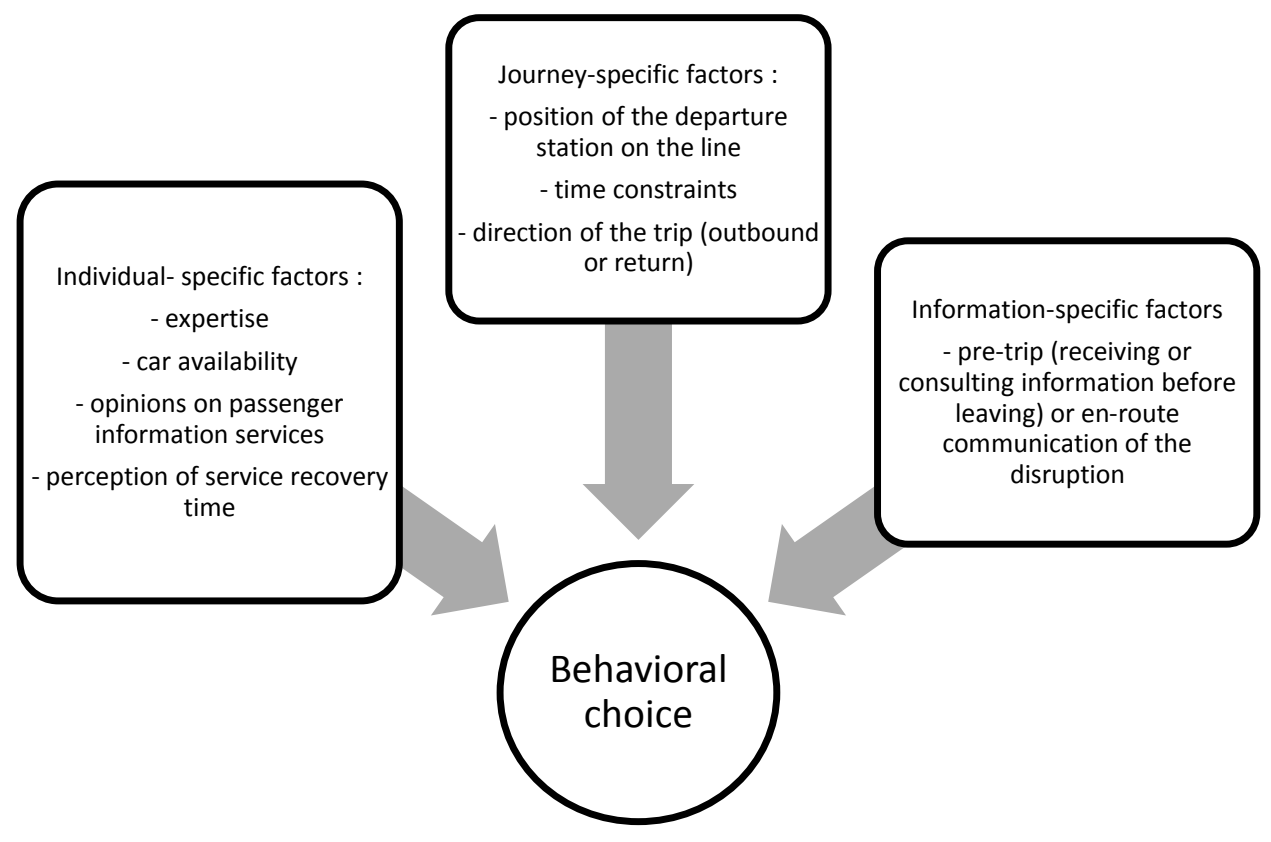

746 Generally speaking, the study confirms the role of the determinants identified by previous studies on driver behavior. More precisely, the results concerning the modalities of these determinants and the associated behaviors tend to be consistent with previous findings. In the paragraphs below, we consider various determinants: individual-specific factors (expertise, car availability, opinions on passenger information, passengers' estimation of their waiting time), journey-specific factors (available transport services, time constraints), and information-specific factors (pre-trip or en-route communication of the disruption). We also describe the determinants identified by other researchers for which we observe no effect on behavior.

With regard to expertise, our research shows passengers with a good understanding of networks and experience with the routes used are more willing to wait than novice users. This result is linked with results obtained on drivers. We know, for example, that habit is important in the inhibition of active decision-making (Van der Horst, 2004) and that individuals with a certain level of knowledge about routes that are familiar to them will be more reluctant to use unfamiliar parts of the network (Chorus \& al., 2006b). This result could also be associated with commuters' inertia, as highlighted by van Excel and Rietveld (2001). Some other hypotheses can be put forward and confirmed by future research. First, perhaps the most experienced passengers know that it is better to wait for a return to normality than change to an overloaded alternative route. Second, the routine of daily trips can lead to a form of resignation that discourages users from making an effort to use another solution. Lastly, experienced passengers could have developed habits during waiting time that make this time more productive. A new study could clarify what waiting entails and consider the 
possibility to delay the start of a trip, which could be a solution used by experts. Existing studies about major disruptions propose this solution in possible answers (Marsden \& al., 2016).

We have also shown that having access to a car encourages passengers to use this mode in the event of a major disruption (Khattan \& Bai, 2018; Nguyen-Phuoc \& al., 2018a). Car availability is linked with respondents' age and socio-occupational group. Thus, observable differences in behavior according to sociodemographic determinants may be mediated by the availability or unavailability of a car.

Regarding opinions, we have shown a possible link between users' opinions about passenger information and the behavior they adopt. More specifically, individuals with an opinion that is in favor of the rapidity, completeness, usability, systematic nature, and reliability of information are likely to change their route in the event of a major disruption. We have not found another study in the literature that tests the impact of this opinion on behavior. We therefore formulate a hypothesis that should be tested by further research. It is possible that a high level of confidence in information encourages a clear evaluation of the situation, low uncertainty and, consequently, proactive decisions.

The diary study allowed us to focus in detail, from a limited number of real cases, on the link between disruptive situations, the passengers involved and their behavior. We were particularly interested not in the link between the real characteristics of the disruption and user choices but in the link between the expected waiting time and choices. If users estimate that their waiting time will exceed 30 minutes, they will implement a strategy not to wait on the spot. Future research could focus on how this assessment works. Moreover, we have shown that this threshold is quite different between individuals.

Concerning the journey-specific factors, the characteristics of the transport system of the place in which individuals find themselves when a disruption occurs has an effect on their decisions. The ease or difficulty with which users can change routes affects their behaviors (Khattan \& Bai, 2018). This was shown by both the RP study and the diary study. When it is difficult to change routes, i.e., when there are few opportunities and those that exist have unacceptable characteristics (extremely long journey time, complexity), other solutions, such as asking for a ride, cancelling the trip or waiting, are preferred. This is especially the case when passengers live in remote outer suburbs where the transport supply is relatively low. In this situation, too, specific habits have been highlighted with regard to traffic information. Users who have a tendency to wait during major disruptions because they have no other solution are reticent with regard to traffic information, seeking it less than others (Peirce \& Lappin, 2004). Indeed, information is useless for them. Then, some of our results indicate 
that time constraints lead individuals to modify their behaviors, but the obtained results are not sufficient to draw conclusions. Additional studies are needed in this area.

Concerning the information-specific factors, learning about the occurrence of a disruption pre-trip or en-route may have a significant impact on users' behavior (Lin \& al., 2016). This was confirmed by the questionnaire and supported by the diary study. Individuals who change to a car tend to subscribe to notifications in order to learn about major disruptions before going to the station. For these individuals, it is very helpful to automatically receive information in real time before leaving for the station and removing car travel from the set of alternatives (Polak \& Jones, 1993). The diary study suggests that user behavior varies depending on the step of the trip when information is received. This variation is confirmed by inter-individual and intra-individual comparisons and in the literature (Lin \& al., 2016).

Finally, some of the possible determinants we have tested do not appear to affect the behavior of passengers in disruptive situations. This applies, in particular, to passengers' personality. In contrast to what was shown by Shiftan, Bekhor and Albert (2011) regarding the role of sensation seeking on the decisions made by motorists, our study detected no such link. In addition, we found no impact for gender, which was identified as an explanatory factor by Zhang, Yun and Yang (2012), and the impact of socio-occupational group was fairly limited.

\subsection{Behavioral profiles}

Based on clustering, we were able to link behavioral patterns, namely, respondents' behavioral solutions in past situations of major disruptions on the outbound and return journey, with explanatory variables identified by bivariate analyses. We identified eight user clusters that became behavioral profiles in the simulation tool. Due to the shortcomings of our sample, the distribution of these classes cannot be considered an accurate representation of the entire population using the studied lines. We nevertheless found some interesting information regarding the different ranges of solutions of the clusters of suburban train passengers. In particular, these classes exhibit marked adaptive behaviors with regard to disruptions. A varying number of characteristics with regard to sociodemographic and geographical factors, vehicle ownership, and individuals' relationship with information are associated with each of these classes. The sample of suburban train passengers is divided into three major clusters and five minor clusters. The major classes contain individuals who change their routes, teleworkers (who have the option of not going to work) and motor vehicle owners (who have access to a car). The minor classes bring together those passengers we called constrained because they have poor transport service for their commute, those who are passive on their return journey, those who are flexible, those who 
choose to be passengers in other vehicles and those who are not obligated to reach their destination on the outbound journey. Regarding users who are "passive on their return journey", we predict they are individuals who have no constraints with regard to their time of arrival at home, particularly in terms of family duties. They are therefore free to take their time in the evening, although they have to arrive at work on time in the morning. Unfortunately, we did not ask any questions about household composition to check this notion. The "leisure users" group seems to be heterogeneous. It is the smallest group in our sample. This is the only group that changes their destination on outbound trips. One hypothesis is that this group is composed of real leisure users and desk-sharers. As we asked no questions about multiple places to work or study, we were not able to better qualify this cluster.

\subsection{Limitations of the study}

We end this discussion by describing the main limitations of our study, which are mainly methodological. Due to a lack of data that would have enabled us to easily identify the users of the studied lines, we were unable to contact more appropriate individuals for our study. This lack of respondents meant we were unable to construct a representative sample that would enable us to make generalizations from the percentages of the profiles we identified in the population using lines N, U and C. Furthermore, the lack of participants, particularly in the case of the diary study, meant we were unable to perform all the comparisons we would have liked to, particularly by highlighting the relation between the trip purpose and the passenger's behavior. Several studies have considered how the purpose of the trip affects passengers' choice behavior, producing strong evidence (Marsden \& al., 2016; NguyenPhuoc \& al., 2018a; van Exel \& Rietveld, 2001). Furthermore, we chose to focus on a limited number of Transilien lines. Thus, it is impossible for us to know whether the findings are transferable to all suburban train users. Thus, the chosen mode of contact induced selection bias since people far from new technologies were not interviewed. Finally, to provide information to simulate passenger flows, the selected scale led us to neglect some micro factors implied in behavioral choices, such as the availability of car parks and congestion. We will consider different solutions for a future study with more participants and will cross our results with a big-data analysis.

\section{Conclusion}

This study contributes to research on the behavior of suburban train passengers in a disruptive situation from three points of view: theoretical, methodological and applicative. From the theoretical standpoint, this research improves our understanding of the behavior of suburban train passengers who are faced with disruptions and the mechanisms behind these 
behaviors. The determinants of behavior we have identified are linked with the individual involved in the disrupted situation, with the journey that is made and with the information given. From the methodological standpoint, we have studied the behavior of users in situations that are as close as possible to reality by implementing a specific repeatedmeasures procedure based on a travel diary. To obtain more data, we also exploited questions that were more disconnected from real disruptions. We thus mixed two RP methods (Shiftan, Bekhor \& Albert, 2011). From the application standpoint, this research, despite its preliminary nature, allowed us to integrate passenger behaviors with multi-agent software that simulates a multimodal transport network (Tschirhart, Adelé, Bauguion \& Tréfond, 2016).

This work also provides some direction for future research. We feel that studies should exploit the first questionnaire to understand the behaviors individuals adopt during disruptions by varying the severity of disruptions. With this questionnaire, we only addressed major disruptions. Thus, we performed a second survey whose results will be published in the near future. We also feel that greater attention should be given to the role played by information and its interpretation in the decision-making process. This will be covered by a new project that will make use of more qualitative methods, such as explanatory interviews (Vermersch, 1994).

For human sciences, producing results for modeling represented a challenge and obliged us to operate at a larger scale than usual. It would be valuable to conduct other multidisciplinary projects, as these have a greater capacity to advance research on the modeling of behaviors in transport systems.

\section{Acknowledgements}

The authors would like to thank SNCF Transilien for their cooperation and invaluable support. We also express our gratitude to Kevin Riley, who translated this article, and AJE, who checked it. This research work contributes to the collaborative project MIC (Modeling, Interoperability, Cooperation). It was carried out in the framework of IRT SystemX, ParisSaclay, France, and therefore was granted public funds within the scope of the French Program "Investissements d'Avenir".

\section{References}

Anable, J., (2005). 'Complacent Car Addicts' or 'Aspiring Environmentalists'? Identifying travel behaviour segments using attitude theory. Transport Policy, 12 (1), 65-78. https://doi.org/10.1016/i.tranpol.2004.11.004 
Baxter, P., \& Jack, S. (2008). Qualitative case study methodology: Study design and implementation for novice researchers. The qualitative report, 13(4), 544-559. Retrieved from https://nsuworks.nova.edu/tar/vol13/iss4/2

Benzécri, J.-P.(1992) Correspondence Analysis Handbook. New York: Marcel Dekker.

Bolger, N., \& Laurenceau, J.-P. (2013). Intensive longitudinal methods: An introduction to diary and experience sampling research. New York: Guilford Press.

Bonsall, P. (2004). Traveler behaviour: decision-making in an unpredictable world. Journal of Intelligent Transportation Systems, 8, 45-60. https://dx.doi.org/10.1080/15472450490437744

Bonsall, P., \& Dunkerley, C. (1997, September). Use of concessionary travel permits in London: results of a diary survey. In Proceedings of Seminar G, European Transport Forum Annual Meeting, Brunel University, England, 1-5 September 1997.

Bonsall, P., \& Palmer, I. (1999). Route Choice in Response to Variable Message Signs: Factors Affecting Compliance. In: R. Emmerink and P. Nijkamp (Eds.), Behavioural and Network Impacts of Driver Information Systems (pp. 181-214). Aldershot: Ashgate.

Brazil, W., Caulfield, B., \& O'Connor, A. (2017). The role of transport information in extreme weather events: A scenario based experiment. Case studies on transport policy, 5(2), 215-223. https://doi.org/10.1016/j.cstp.2017.02.001

Chorus, C.G. (2012). What about behaviour in travel demand modelling? An overview of recent progress. Transportation Letters, 4 (2), 93-104. https://dx.doi.org/10.3328/TL.2012.04.02.93-104

Chorus, C. G., Arentze, T. A., Molin, E. J. E., Timmermans, H. J. P., \& Van Wee, G. P. (2006a). Use and Effects of Advanced Traveler Information Services, Transport Reviews, 26(2), 127-149. https://dx.doi.org/10.1080/01441640500333677

Chorus, C. G., Arentze T. A., Timmermans H. J. P., Molin, E.J.E., \& Van Wee, B. (2007). Travelers' Need for Information in Traffic and Transit: Results from a Web Survey. Journal of Intelligent Transportation Systems, 11 (2), 57-67. https://dx.doi.org/10.1080/15472450701293841

Chorus, C., Molin, E., \& van Wee, B. (2006b). Travel information as an instrument to change car drivers' travel choices: a literature review. European Journal of Transport and Infrastructure Research, 6(4), 335-364. Retrieved from http://www.ejtir.tudelft.nl/issues/2006 04/pdf/2006 04 03.pdf

Elia, E.B., Erev, I., \& Shiftan, Y. (2008). The combined effect of information and experience on drivers' route-choice behavior. Journal of Transportation, 35 (2), 165-177. https://dx.doi.org/10.1007/s11116-007-9143-7

Emmerink, R. H. M., Nijkamp, P., Rietveld, P., \& Van Ommeren, J. N. (1996). Variable message signs and radio traffic information: an integrated empirical analysis of drivers' route choice behaviour. Transportation Research Part A, 30(2), 135-153. https://doi.org/10.1016/0965-8564(95)00016-X 
Gärling, T., \& Axhausen, K. W. (2003). Introduction: Habitual travel choice. Transportation, 30(1), 1-11. https://doi.org/10.1023/A:1021230223001

Gärling, T., Fujii, S., \& Boe, O. (2001). Empirical tests of a model of determinants of scriptbased driving choice. Transportation Research Part F, 4 (2), 89-102. https://doi.org/10.1016/S1369-8478(01)00016-X

Golightly, D., \& Dadashi, N. (2017). The characteristics of railway service disruption: implications for disruption management. Ergonomics, 60(3), 307-320. https://doi.org/10.1080/00140139.2016.1173231

Greenacre, M. (2017). Correspondence Analysis in Practice, Third Edition. London: Chapman \& Hall/CRC.

Grison, E., Gyselinck, V., \& Burkhardt, J. M. (2016). Exploring factors related to users' experience of public transport route choice: influence of context and users profiles. Cognition, Technology \& Work, 18(2), 287-301. https://doi.org/10.1007/s10111-015$\underline{0359-6}$

Haustein, S., \& Hunecke, M. (2013). Identifying target groups for environmentally sustainable transport: assessment of different segmentation approaches. Current Opinion in Environmental Sustainability, 5(2), 197-204. https://doi.org/10.1016/j.cosust.2013.04.009

Hunecke, M., Haustein, S., Böhler, S., \& Grischkat, S. (2010). Attitude-based target groups to reduce the ecological impact of daily mobility behavior. Environment and behavior, 42(1), 3-43. https://doi.org/10.1177/0013916508319587

Jou, R.-C. (2001). Modeling the impact of pre-trip information on commuter departure time and route choice, Transportation Research Part B, 35, 887-902. https://doi.org/10.1016/S0191-2615(00)00028-X

Khattak, A. J., Yim, Y. \& Stalker, L. (1999). Does Travel Information Influence Commuter and Non commuter Behavior? Results from the San Francisco Bay Area TravInfo Project. Transportation Research Record, 1694, 48-58. https://dx.doi.org/10.3141/1694-07

Kattan, L., \& Bai, Y. (2018). LRT passengers' responses to advanced passenger information system (APIS) in case of information inconsistency and train crowding. Canadian Journal of Civil Engineering, 45(7), 583-593. https://doi.org/10.1139/cjce-2017-0559

Kitamura, R., Jovanis, P., Abdel-Aty, M., Vaughn, K., \& Reddy, P. (1999). Impact of Pre-trip and En-route Information on Commuters' Travel Decisions: Summary of Laboratory and Survey-based Experiments from California. In: R. Emmerink and P. Nijkamp (Eds.), Behavioural and Network Impacts of Driver Information Systems (pp. 241267). Aldershot: Ashgate.

Le Roux, B., \& Rouanet, H. (2010). Multiple Correspondence Analysis. Thousand Oaks: SAGE Publications.

Le Roux, B., \& Rouanet, H. (2004). Geometric Data Analysis : from Correspondence Analysis to structured Data Analysis. Durdrecht: Kluwer. 
Lin, T., Shalaby, A., \& Miller, E. (2016). Transit user behaviour in response to service disruption: state of knowledge. Presented at the 51st Annual Conference of the Canadian Transportation Research Forum, Toronto, Ontario, Canada.

Lin, T., Srikukenthiran, S., Miller, E., \& Shalaby, A. (2018). Subway user behaviour when affected by incidents in Toronto (SUBWAIT) survey-A joint revealed preference and stated preference survey with a trip planner tool. Canadian Journal of Civil Engineering, 45(8), 623-633. https://doi.org/10.1139/cjce-2017-0442

Marsden, G., Anable, J., Shires, J., \& Docherty, I. (2016). Travel behaviour response to major transport system disruptions: Implications for smarter resilience planning. International Transport Forum Discussion Paper.

Marsden, G., \& Docherty, I. (2013). Insights on disruptions as opportunities for transport policy change. Transportation Research Part A, 51, 46-55. https://doi.org/10.1016/j.tra.2013.03.004

Martin, A., Adelé, S., \& Reutenauer, C. (2016). Stratégies du voyageur : analyse croisée d'entretiens semi-directifs. Actes du colloque JADT 2016, Nice, France. Retrieved from https://jadt2016.sciencesconf.org/82539/document

Nguyen-Phuoc, D., Currie, G., De Gruyter, C., \& Young, W. (2018a). How do public transport users adjust their travel behaviour if public transport ceases? A qualitative study. Transportation Research Part F, 54, 1-14. https://doi.org/10.1016/..trf.2018.01.009

Nguyen-Phuoc, D. Q., Currie, G., De Gruyter, C., \& Young, W. (2018b). Transit user reactions to major service withdrawal-A behavioural study. Transport Policy, 64, 2937. https://doi.org/10.1016/j.tranpol.2018.01.004

Outwater, M., Castleberry, S., Shiftan, Y., Ben-Akiva, M., Zhou, Y., \& Kuppam, A. (2003). Attitudinal market segmentation approach to mode choice and ridership forecasting: structural equation modeling. Transport Research Record, 1854 (1), 32-42. https://dx.doi.org/10.3141/1854-04

Peeta, S., \& Ramos, J.L. Jr (2006). Driver response to variable message signs-based traffic information. IEE Proceedings - Intelligent Transport Systems, 153 (1), 2-10. https://dx.doi.org/10.1049/ip-its:20055012

Peirce, S., \& Lappin, J. (2004). Why don't more people use advanced traveler information? Evidence from the Seattle area. Paper presented at the 83rd Meeting of the Transportation Research Board, Washington, DC, USA.

Pender, B., Currie, G., Delbosc, A., \& Shiwakoti, N. (2013). Disruption recovery in passenger railways: International survey. Transportation Research Record, 2353(1), 22-32. https://doi.org/10.3141/2353-03

Piner, D., Condry, B. (2017). International best practices in managing unplanned disruption to suburban rail services. Transportation Research Procedia, 25, 4403-4410. 4410. https://doi.org/10.1016/j.trpro.2017.05.331

Polak, J., \& Jones, P. (1993). The acquisition of pre-trip information: A stated preference approach. Transportation, 20, 179-198. https://dx.doi.org/10.1007/BF01307058 
Pronello, C., \& Camusso, C. (2011). Travelers' profiles definition using statistical multivariate analysis of attitudinal variables. Journal of Transport Geography, 19, 1294-1308. https://doi.org/10.1016/i.jtrangeo.2011.06.009

Schwanen, T., Banister, D., \& Anable, J. (2012). Rethinking habits and their role in behaviour change: the case of low carbon mobility. Journal of Transport Geography, 24, 522532. https://doi.org/10.1016/j.jtrangeo.2011.06.009

Shiftan, Y., Bekhor, S., \& Albert, G. (2011). Route choice behaviour with pre-trip travel time information. IET Intelligent Transport System, 5 (3), 183-189. https://doi.org/10.1049/iet-its.2010.0062

Simon, H. A. (1955). A behavioral model of rational choice. The quarterly journal of economics, 59, 99-118. Available at http://www.jstor.org/stable/1884852

Teng, J., \& Liu, W. R. (2015). Development of a behavior-based passenger flow assignment model for urban rail transit in section interruption circumstance. Urban Rail Transit, 1(1), 35-46.

Tschirhart, F., Adelé, S., Bauguion, P.O., Tréfond, S. (2016). Modeling the multimodal mass transit system and its passengers. Proceedings of WCRR 2016, Milan, Italy.

United Nations Department of Economic and Social Affairs, Population Division (2015). World Urbanization Prospects: The 2014 Revision, (ST/ESA/SER.A/366). Available at https://esa.un.org/unpd/wup/Publications/Files/WUP2014-Report.pdf

Van Berkum, E., \& Van der Mede, P. (1999). Driver Information and the De(formation) of Habit in Route Choice. In: R. Emmerink and P. Nijkamp (Eds.), Behavioural and Network Impacts of Driver Information Systems (pp. 155-178). Aldershot: Ashgate.

Van der Horst, R. (2004). Use of travel information and effects on location choice for recreational trips, European Transport Conference. Available at http://abstracts.aetransport.org/paper/download/id/2032

Van der Hurk, E., Kroon, L., Li, T., Maroti, G., \& Vervest, P. (2010). Using Smart Card Data for Better Disruption Management in Public Transport. Proceedings 11th Trail Congress. Retrieved from http://rstrail.nl/new/wp-content/uploads/2015/02/Hurk 0.pdf

Van Exel, N. J. A., \& Rietveld, P. (2009). When strike comes to town... anticipated and actual behavioural reactions to a one-day, pre-announced, complete rail strike in the Netherlands. Transportation research part A: policy and practice, 43(5), 526-535. https://doi.org/10.1016/j.tra.2009.01.003

Van Exel, N. J. A., \& Rietveld, P. (2001). Public transport strikes and traveller behaviour. Transport Policy, 8(4), 237-246. https://doi.org/10.1016/S0967-070X(01)00022-1

Vermersch, P. (1994). L'entretien d'explicitation. Paris : Esf.

Verplanken, B. (2006). Beyond frequency: habits as mental construct. British Journal of Social Psychology, 45 (3), 639-656. https://doi.org/10.1348/014466605X49122 
Yin, R. K. (2003). Case study research: Design and methods (3rd ed.). Thousand Oaks, CA: Sage.

Zanni, A. M., \& Ryley, T. J. (2015). The impact of extreme weather conditions on long distance travel behaviour. Transportation Research Part A: Policy and Practice, 77, 305-319. https://doi.org/10.1016/j.tra.2015.04.025

Zhang, Y., Yun M., \& Yang, X. (2012). Who will use pretrip traveler information and how will they respond? Preliminary study in Zhongshan China, 91st TRB Annual Meeting.

Zhu, S., \& Levinson, D. M. (2012). Disruptions to transportation networks: a review. In Network reliability in practice (pp. 5-20). New York, NY: Springer.

Zuckerman, M. (1994). Behavioral expressions and biosocial bases of sensation seeking. Cambridge University Press.

Zuckerman, M., Kolin, E. A., Price, L., \& Zoob, I. (1964). Development of a sensation-seeking scale. Journal of consulting psychology, 28(6), 477-482.

https://dx.doi.org/10.1037/h0040995 